Working Paper No. 600, 2003

\title{
Organized Crime, Corruption and Punishment
}

by Maurice Kugler, Thierry Verdier and Yves Zenou

IUI, The Research Institute of Industrial Economics

P.O. Box 5501

SE-114 85 Stockholm

Sweden 


\title{
Organized Crime, Corruption and Punishment*
}

\author{
Maurice Kugler $^{\dagger} \quad$ Thierry Verdier ${ }^{\ddagger} \quad$ Yves Zenou $^{\S}$ \\ January 28, 2003 (Revised October 21, 2003)
}

\begin{abstract}
We analyze an oligopoly model in which differentiated criminal organizations globally compete on criminal activities and engage in local corruption to avoid punishment. When law enforcers are sufficiently well-paid, difficult to bribe and corruption detection highly probable, we show that increasing policing or sanctions effectively deters crime. However, when bribing costs are low, that is badly-paid and dishonest law enforcers work in a weak governance environment, and the rents from criminal activity relative to legal activity are sufficiently high, we find that increasing policing and sanctions can generate higher crime rates. In particular, the relationship between the traditional instruments of deterrence, namely intensification of policing and increment of sanctions, and crime is nonmonotonic. Beyond a threshold, increases in expected punishment induce organized crime to corruption, and ensuing impunity leads to higher rather than lower crime.
\end{abstract}

JEL Classification: K42, L13.

Keywords: Deterrence, organized crime, corruption, oligopoly, free entry.

${ }^{*}$ We would like to thank the participants of the CEPR Public Policy Symposium, La Coruña, Spain, 18-19 October 2002, Edward Christie, the editor Sören Blomquist and two anonymous referees for very helpful comments. Yves Zenou thanks the Marianne and Marcus Wallenberg Foundation for financial support.

${ }^{\dagger}$ Department of Economics, University of Southampton, Southampton SO17 1BJ, United Kingdom, and Center for Research on Economic Development and Policy Reform, Stanford University, Stanford CA 94305. E-mail: mkugler@stanford.edu.

‡DELTA-ENS, 48 boulevard Jourdan, 75014 Paris, France. E-mail: verdier@delta.ens.fr

${ }^{\S}$ Corresponding author. IUI, University of Southampton and GAINS. Address: IUI, The Research Institute of Industrial Economics, Box 5501, 11485 Stockholm, Sweden. E-mail: yvesz@iui.se 


\section{Introduction}

There are occasional examples of successful battles against the corruption perpetrated by criminal organizations to influence law enforcement and politics. For example, in 1931, right after prohibition of alcohol consumption ended in the United States, the conviction of the notorious gang leader Al Capone for tax evasion led to the break up of mobs and rackets built around the distribution of alcohol, and other complementary activities. Yet, failed attempts to curb the influence of organized crime are common place. Recently, in Italy, the investigation mani pulite (clean hands) initiated by a courageous group of judges disintegrated after disclosing pervasive corruption by the Mafia, due to a string of assassinations inflicted upon law enforcers and their families. In general, organized crime syndicates are very difficult to eliminate. They are able to protect themselves by a combination of means: (i) Physical violence against informants and witnesses, $(i i)$ violent threats against prosecutors, judges and members of juries, (iii) corruption of law-enforcement officials, (iv) Use of lawyers to manipulate the legal system, and $(v)$ financial contributions to political campaigns.

The objective of this paper is to better understand the complex relationship between organized crime, corruption and the efficiency of the justice system. We will in fact focus on the evasion from conviction by criminal organizations through bribing law enforcers. However, the relevance of our findings is not confined to the influence on the operation of the legal system exerted through this channel. As long as organized crime can invest to manipulate the incentives faced by the actors involved in making prosecution possible, our results obtain regarding the limited effectiveness of typical crime deterrents in weak governance environments.

Criminal gangs are active and clever in their efforts to bribe policemen. Cooperative police officers are helpful to criminal gangs by passing information to them about police investigations and planned raids, and by making deliberate 'mistakes' in prosecutions. Such technical errors then ensure that the charges against the criminals will not result in guilty verdicts. Corruption of police officers is made easier by the fact that they are modestly paid and, therefore, are subject to temptation. Moreover, like prosecutors and members of juries, law enforcers can be coerced through violence. Also, once a few po- 
licemen have been corrupted, they will make strong efforts to ensure that their colleagues are also corrupted. An honest policeman who tries to inform on his corrupt colleagues will come under the most severe pressures from them.

The literature on crime has emphasized the deterrence capacity of the justice system on criminal activities (e.g. Becker 1968, Ehrlich, 1973, Levitt, 1998). Recent evidence for the United States tends to support the hypothesis that the expectations of potential criminals with respect to punishment determine crime rates (see e.g. Levitt, 1997). Yet, expected punishment depends not only on the severity of sentences but also on the probability of conviction once crime is perpetrated. The latter depends on detection by the police, prosecution by attorneys and the deliberation of judges and juries. As long as these three activities are conducted transparently and efficiently, tough sanctions will deliver deterrence of criminal activity. ${ }^{1}$ However if, as described above, corruption is pervasive, then the efficiency in law enforcement can be very much reduced.

Since Becker and Stigler (1974) acknowledge that malfeasance by enforcers can diminish the effectiveness of laws and sanctions in controlling crime, the literature on crime has considered the problem of bribed officials. ${ }^{2}$ They propose the payment of efficiency wages to prevent bribe taking. Besley and McLaren (1993) and Mookherjee and Png (1995) also propose wage regimes to mitigate the moral hazard problem when rent seekers attempt to co-opt law enforcers. Like Becker and Stigler (1974), Bowles and Garoupa (1997) consider a model in which bribery reduces punishment and thus deterrence. However, the focus is different since it is on the effects of bribery on the optimal allocation of resources (which incorporates the social costs of both crime and corruption) within the public enforcement agency. They show that the maximal fine may not be optimal. Chang et al. (2000) extend Bowles and Garoupa (1997) by introducing psychological costs (or social norms) of caught corrupt officers. They show that, when corruption is widespread, social norms can no longer take a sufficient sanction against a corrupt officer, and raising fines can in fact

\footnotetext{
${ }^{1}$ It is also well-known that, when expected punishment is itself endogenous and negatively depends on the number of criminals, multiple equilibria in crime and deterrence may emerge (see for instance Fender, 1999, or Sah, 1991).

${ }^{2}$ For a comprehensive survey on law enforcement, see Polinski and Shavell (2000). Also, for a general survey on corruption and governance, see Bardhan (1997).
} 
result in more crime. Another extension of Bowles and Garoupa (1997) is done by Garoupa and Jellal (2002). They consider the role of asymmetric information on the emergence of collusion between criminals and enforcers. They show that asymmetric information about the private costs of enforcers engaging in collusion might eventually deter corruption and bargaining between the two parties. Finally, Basu et al. (1992) argue that when the possibility of collusion between law enforcing agents and criminals is introduced, control of corruption becomes more difficult than is suggested by the standard Beckerian approach. Marjit and Shi (1998) extend this paper and show that controlling crime becomes difficult, if not impossible, because the probability of detection can be affected by the effort of a corrupt official. Finally, in a recent paper Polinski and Shavell (2001) consider the dilution of deterrence caused by corruption not only due to bribing by criminals but also extortion of the innocent by crooked enforcers. They propose rewards for corruption reports to mitigate the breakdown of deterrence. Our approach differs from the literature in that we focus is on the relationship between organized crime ${ }^{3}$ corruption and punishment in the context of imperfect competition. Hence, we find not only a reduction in deterrence effectiveness due to corruption as in previous models but actually a potential reversal whereby policies usually associated with crime deterrence can become inducements as long as bribery remains unchecked.

In the present paper, we analyze the role of corruption not only in diluting deterrence but also as a strategic complement to crime and therefore a catalyst to organized crime. For that, we develop a simple oligopoly model in which $n$ criminal organizations compete with each other on the levels of both criminal activities and corruption. We first show that when the cost of bribing judges or the number of criminal organizations increases, then both crime and corruption decrease whereas when the profitability of crime increases, then both crime and corruption increase. We then show our main results. If corruption is costly, due to law enforcers being well-paid, hard to bribe and easily detected when accepting side payments, relative to the profits from crime, then, as predicted by the standard literature on crime, it is always effective to reduce crime by intensifying policing or toughening sanctions. However, in the reverse case of low-paid dishonest law enforcers under weak governance and sizable rents

\footnotetext{
${ }^{3}$ There is a small theoretical literature on organized crime (without corruption). See in particular Fiorentini and Peltzman (1996), Garoupta (2000) and Mansour et al. (2000).
} 
from illegal activity relative to the outside lawful options, increasing policing or sanctions may in some cases generate higher crime rates.

This last result is fairly intuitive. As long as the return to legal economic activity is sufficiently low relative to rents from crime, gangs continue pursing crime. When sanctions and policing are toughened, the cost of hiring criminals rises as there is a wage premium to compensate for the risk of conviction if apprehended. This will discourage crime but only up to a point. In particular, if bribing costs are small relative to the rents from crime, there is level of expected punishment beyond which further toughening of sanctions will induce increasingly higher levels of corruption, and of ensuing crime. Indeed, when governance is weak, harsher punishment can be a catalyst for organized crime and may lead to concentration of criminal rents and higher rates of return ex post. For example, in the 1920's during alcohol prohibition in the United States, mob activities were so profitable that organized crime could afford to keep in its payroll government officials at various levels, including elected politicians and law enforcers, to influence the legal system in its favor. Therefore, the potential effectiveness of tough sentencing as an effective policy to stop organized crime and other subsidiary illegal activities is limited. This does not imply that tough sanctioning of crime and policing should be abandoned altogether when institutional checks and balances are underdeveloped. But, rather that unless corruption is curbed, traditional deterrence policies can have the perverse effect of making crime and corruption strategic complements.

We then show that our results are robust when criminal organizations can freely enter the crime market. Indeed, when the fixed cost of entry is bounded both below and above, we show that increasing sanctions can in fact increase the local and global levels of corruption and crime.

After this introduction, Section 2 sets up the model by describing the problem of the criminal organization. Section 3 characterizes the corruption market. In Section 4, the interaction between crime and corruption is analyzed and the main propositions are presented. Section 5 analyzes the free-entry equilibrium. Finally, Section 6 concludes the paper by discussing some implications of the results obtained. 


\section{The model}

There are $n$ criminal organizations in the economy. These organizations compete with each other on crime but are local monopsonies in the corruption market. On the crime market (think for example of drug cartels), there is a pie to be shared and Cournot competition takes place. On the corruption market, there is a continuum of judges to bribe for each of the $n$ criminal organizations. As this will become clear below, crime is global whereas corruption is local.

Let us first describe the profit function. For each criminal organization, the revenue from criminal activities depends on the number of crimes and the size of the booty per crime. The cost is given by the wage bill accruing the criminals and the bribes paid to avoid conviction when crimes are detected. For the criminal organization $i=1, \ldots, n$, profits are given by:

$$
\pi\left(C, C_{i}, \alpha\right)=B(C) C_{i}-w_{i} L_{i}-T_{i}
$$

where

$$
C=\sum_{j=1}^{j=n} C_{j}
$$

is the total number of crimes perpetrated in the economy, $C_{i}$ denotes the number of crimes committed by organization $i, B(C)$ is the booty per crime for all criminal organizations, with $B^{\prime}(C)<0$ (the booty per crime $B(C)$ is assumed to decrease as the number of crimes increases), $w_{i}$ is the wage paid by each criminal organization $i$, determined below, to their $L_{i}$ employed criminals, and $T_{i}$ are the total costs to bribe judges borne by the criminal organization $i$. To be explicitly determined below. For simplicity, we assume about crime profitability and technology that $B(C)=B-C$ and $C_{i}=L_{i}$.

Let us determine the wage $w_{i}$. Each worker/criminal is risk neutral. The participation constraint for a given criminal working in organization $i$ is given by:

$$
\phi\left[w_{i}-\left(\alpha_{i} .0+\left(1-\alpha_{i}\right) S\right)\right]+(1-\phi) w_{i} \geq w_{0}
$$

where $0<\phi<1$ is the probability of detection of a crime, $\alpha_{i}$ denotes the probability that a judge is corrupted by organization $i, S>0$ is the sanction when punishment of detected crime is enforced and $w_{0}>0$ is the outside wage if the individual has a regular job and is not a criminal. Take equation (2). 
The left hand side gives the expected gain of a criminal. Indeed, if he/she is not caught (with probability $1-\phi$ ), he/she gets $w_{i}$. If he/she is caught (with probability $\phi$ ), he/she still obtains $w_{i}$ (we assume that criminals get their wage even when they are caught); if the judge is corrupted by organization $i$ (with probability $\alpha_{i}$ ), the criminal has no sanction whereas if the judge is not corrupted by organization $i$ (with probability $1-\alpha_{i}$ ), the criminal has a sanction $S$ (for example number of years in prison). This is key incentive for a criminal to work for an organization since, apart from $w_{i}$, he/she benefits from protection (especially corrupted judges).

In equilibrium, this constraint is bidding since there is no incentive for the criminal group to pay more than the outside wage. Therefore, the reservation wage for which workers accept to commit crime for organization $i$ is equal to:

$$
w_{i}=\phi S\left(1-\alpha_{i}\right)+w_{0}
$$

Interestingly, in equilibrium, this wage will be determined by the level of corruption $\alpha_{i}$ in each organization since the higher the level of corruption, the lower this wage. Indeed, if the risk to be prosecuted for a criminal is low, then, as long as $w_{i}$ is greater $w_{0}$ (which is always the case; see $(3)$ ), there is no need to pay a high wage.

\section{Corruption}

The interaction between criminal organizations and judges is modeled here by means of a monopsonistic competitive market inspired by Salop (1979). For that, we consider $n$ local markets (for example regions or local areas); each of them is described by the circumference of a circle which has length 1 . In each local market, there is one criminal organization and a continuum of judges uniformly distributed on the circumference of the circle; the density is constant and equal to 1 . Without loss of generality, organization $i$ 's $(=1, \ldots n)$ location is normalized to 0 . The space in which each criminal organization and judges are located is interpreted as the "transaction cost" space. As a result, criminal organizations compete with each other on crime, i.e. crime is global, whereas they only corrupt judges locally, i.e. corruption is local. This means that, if a criminal belonging to organization $i$ is caught, he/she will be prosecuted by a judge located in market $i$. In other words, criminals commit 
crime everywhere but are only prosecuted in the region where they are coming from. For example, for the drug business, it implies that criminal organizations via their "employees" sell drug everywhere but their criminals are prosecuted where they live.

Contrary to the standard spatial model (Salop, 1979), the horizontal differentiation of judges is from the point of view of criminal organizations. In other words, the latter are paying all the transaction costs needed to bribe a judge. From the judge's point of view, there is no differentiation since they will accept a bribe if and only if their expected gain is greater than their current wage. As a result, the "distance" of a judge to a criminal organization reflects the transaction cost necessary to agree on a bribe. If we take for example the case of Italy, it is clear that it is easier for a criminal organization located in Sicily to bribe a judge located in Palermo than in Milan because it has more contacts with local people and also speak the same dialect.

Judges' location types are denoted by $x$. The higher the distance, the higher is the (transaction) cost to bribe a judge. The transaction cost function between a criminal organization located in 0 and a judge $x$ is $t|x|$, where $t$ expresses the transaction cost per unit of distance in the location space. We assume that the outside option of a judge is $w_{b}$, i.e. the latter is the current wage of the judge.

In this paper, we focus on non-covered (corruption) markets, i.e. markets in which some of the judges do not accept bribes and are thus not corrupted. We believe it is much more realistic than a covered market in which all judges will be corrupted in equilibrium. This means that each criminal organization acts as a (local) monopsony on the corruption market whereas they will compete a la Cournot on the crime market. Denote by $\bar{x}_{i}$ the boundary of the area of each monopsonist $i$, which implies that each criminal organization will bribe $2 \bar{x}_{i}$ judges in equilibrium. Since each criminal organization is alone in the corruption market, we have to check that $\bar{x}_{i}<1 / 2, \forall i=1, \ldots, n$, so that, in equilibrium, the corruption market is not covered. Observe that, even if the prosecution and thus the corruption are local, the probability to be prosecuted by a corrupted judge is never 1 . Indeed, when a criminal belonging to organization $i$ is caught, one knows that he/she will be judged in region $i$ but one does not know the judge to which the case has been assigned. This is why the probability to be prosecuted by a corrupted judge in region $i$ is $2 \bar{x}_{i}$, which is 
obviously strictly less than 1 .

All judges are risk neutral. The participation constraint for a judge who is bribed by a criminal organization $i$ located at a distance $x_{i}$ is thus given by

$$
(1-q)\left(f+w_{b}\right) \geq w_{b}
$$

where $q$ is the probability that corruption is caught (quite naturally, we assume that if a judge is caught, he/she loses his/her wage $w_{b}$ ) and $f$ is the bribe given to the judge. Observe that $f$ is not indexed by $i$ since on the corruption market each criminal organization has total monopsony power and thus fixed a bribe that just binds the judge's participation constraint; the latter only depends on $q$ and $w_{b}$. Once again, the left hand side gives the expected benefit from corruption whereas the right hand side describes the gain from no-corruption. The sanction for corruption is the loss of the job and the bribe is lost as criminals receive no protection. As a result, for each organization $i=1, \ldots, n$ the bribe necessary to corrupt a judge is given by

$$
f=\frac{q}{1-q} w_{b}
$$

As stated above, all judges are identical so that at $f$ they will always accept a bribe (we could have assumed that the bribe is $f+\varepsilon$, where $\varepsilon$ is very small but positive; this would obviously not change our results so whenever judges are indifferent they accept to be bribed). However, from the criminal organization's point of view each judge is not located at the same "distance" so that the transaction cost to bribe a judge is different from one judge to another. Since $\bar{x}_{i}$ is the maximum "distance" acceptable for each criminal organization $i$ (i.e. beyond $\bar{x}_{i}$ the transaction cost of bribing a judge is too high), then the total transaction costs for each criminal organization $i$ is given by: ${ }^{4}$

$$
T_{i}=2 \int_{0}^{\bar{x}_{i}}(f+t) x d x=(f+t) \bar{x}_{i}^{2}
$$

\footnotetext{
${ }^{4}$ If we take a geographical interpretation, then the total cost $(f+t) x$ of bribing a judge located at a distance $x$ from a criminal organization is as follows. The criminal organization has to "travel" a distance $x$, at a cost $t$ per unit of distance, to see the judge and then has to bribe him/her, at a cost $f$ per unit of distance, i.e. the cost of bribing a judge depends on the physical distance between this judge and the criminal organization . In fact, we assume that there is a perfect correlation between the physical distance and the bribe distance between a criminal organization and a judge, even though the cost per unit of distance is different, i.e. $t \neq f$.
} 
In this context, since the length of the circumference of the circle is normalized to 1 , the probability $\alpha_{i}$ (the fraction of law enforcers that will be bribed in equilibrium by paying to each of them a bribe $f$ ) is given by $\alpha_{i}=2 \bar{x}_{i} / 1=2 \bar{x}_{i}$.

Taking into account all the elements (in particular the participation constraint of the criminal (3) and the participation constraint of each judge), and using (1), the profit function of a criminal group can be written as:

$$
\pi\left(C, C_{i}, f\right)=\left(B-\sum_{j=1}^{j=n} C_{j}\right) C_{i}-\left[\phi S\left(1-2 \bar{x}_{i}\right)+w_{0}\right] C_{i}-(f+t) \bar{x}_{i}^{2}
$$

This profit function of each criminal organization is divided in three parts. The first one is the proceeds from crime, which depends on the competition in the crime market between the different crime organizations. The second corresponds to the salary costs of hiring criminals while the third part denotes the costs of bribing judges.

\section{Crime and corruption}

As stated above, criminal organizations compete on both crime and corruption. On the crime market, each criminal organization $i$ competes a la Cournot by determining the optimal $C_{i}$. On the corruption market, each acts as local monopsonist by determining the optimal $\bar{x}_{i}$ (indeed, they have to determine the maximum distance $\bar{x}_{i}$ beyond which it is not profitable corrupting a judge). Because, in this model, judges are basically permanent employees of criminal organizations, the choices of $C_{i}$ and $\bar{x}_{i}$ are simultaneous. Thus, choosing simultaneously $C_{i}$ and $\bar{x}_{i}$ (observe that there is a one-to-one relationship between $\bar{x}_{i}$ and $\alpha_{i}$ ) that maximize the profit (5) yields the following first order conditions:

$$
\begin{gathered}
B-\sum_{j=1}^{j=n} C_{j}-C_{i}-\left[\phi S\left(1-2 \bar{x}_{i}\right)+w_{0}\right]=0 \\
2 \phi S C_{i}-2(f+t) \bar{x}_{i}=0
\end{gathered}
$$

Using the Hessian matrix, it is easy to verify that the profit function (5) is strictly concave (implying a unique maximum) if and only if:

$$
f+t>2(\phi S)^{2}
$$


Let us now focus on a symmetric equilibrium in which $C_{i}=C_{j}=C^{*}$ and $\bar{x}_{i}=\bar{x}_{j}=\bar{x}^{*}$. These two first order conditions are now given by:

$$
\begin{aligned}
B-(n+1) C^{*} & =\phi S\left(1-2 \bar{x}^{*}\right)+w_{0} \\
\phi S C^{*} & =(f+t) \bar{x}^{*}
\end{aligned}
$$

Now, from (9) we obtain

$$
C^{*}=\frac{B-w_{0}-\phi S\left(1-2 \bar{x}^{*}\right)}{n+1}
$$

Plugging (11) into (10) yields

$$
\bar{x}^{*}=\frac{\phi S\left(B-w_{0}-\phi S\right)}{(f+t)(n+1)-2(\phi S)^{2}}
$$

Then, by plugging (12) into (11), we have

$$
C^{*}=\frac{(f+t)\left(B-w_{0}-\phi S\right)}{(f+t)(n+1)-2(\phi S)^{2}}
$$

We have finally the following result.

\section{Proposition 1 Assume}

$$
\phi S<\min \left[\sqrt{(f+t) / 2}, B-w_{0}, \frac{(f+t)(n+1)}{2\left(B-w_{0}\right)}\right]
$$

Then, there is a unique equilibrium $C^{*}$ and $\alpha^{*}=2 \bar{x}^{*}$, where the number of crime per criminal organization $C^{*}$ is given by (13) and the number of corrupted judges per criminal organization $\alpha^{*}=2 \bar{x}^{*}$ by (12). Both of them are strictly positive and $\left(1-\alpha^{*}\right) n$ judges are not corrupted in equilibrium. Moreover, the equilibrium profit of each criminal organization is given by

$$
\pi^{*}(n)=\frac{(f+t)\left(B-w_{0}-\phi S\right)^{2}\left(f+t-(\phi S)^{2}\right)}{\left[(f+t)(n+1)-2(\phi S)^{2}\right]^{2}}>0
$$

and the wage paid to each criminal is equal to

$$
w^{*}(n)=\phi S \frac{(f+t)(n+1)-2 \phi S\left(B-w_{0}\right)}{(f+t)(n+1)-2(\phi S)^{2}}+w_{0}>w_{0}
$$

Proof. See Appendix 1.

The following comments are in order. First, condition (14) guarantees that both $C^{*}$ and $\bar{x}^{*}$ are strictly positive and that the solution of the maximization 
problem is unique. Condition (14) also ensures that, in equilibrium, some judges are not corrupted (i.e. $\bar{x}^{*}<1 / 2$ ). Indeed, the difference between the booty $B$ and the wage of an individual having a regular job (i.e. working in the "legal" sector) has to be large enough to induce criminal organizations to hire criminals and to bribe judges but at the same time its has to be bounded above otherwise all judges will be corrupted because the profit of each organization would be too large. Second, when choosing $C^{*}$ the optimal number of criminals to hire, each criminal organization faces two opposite effects. When it increases $C$, the proceeds from crime is higher (positive loot effect) but the competition will be fiercer (negative competition effect) and the salary costs higher (negative salary effect). As a result, choosing the optimal $C^{*}$ results of a trade-off between the first positive effect and the second and third negative effects. This trade-off is reflected in the first order condition (9). Finally, when choosing $\bar{x}^{*}$ the level of corruption, each criminal organization only faces two effects (there is no competition since each criminal organization acts as a monopsonist in the corruption market). Indeed, when it increases $\bar{x}$, each criminal's salary becomes less costly (positive salary effect) since criminals have less chance to be sentenced but the costs of bribing judges increase (negative bribe effect). This trade-off is reflected in the first order condition (10).

At this stage, it is important to question the timing of the model in which the choices of $C_{i}$ and $\bar{x}_{i}$ are simultaneous, implying that some judges are basically permanent employees of criminal organizations. Another possibility would have been that criminal organizations commit crimes first, and then, when detected, invest resources to bribe the judge to which the case has been assigned. In that case, the timing would have been that $C_{i}$ is chosen first and then $\bar{x}_{i}$ is decided. It is easy to verify that using this timing, we would have obtained exactly the same results than using the simultaneous choice timing, i.e. $C^{*}$ and $\bar{x}^{*}$ will still be given by (13) and (12). This is because in both cases crime has not strategical effects on corruption, i.e. $C_{-i}$ (crimes committed by all other criminals but $i$ ) has no effect on $\bar{x}_{i}$ (see equation (7)) However, if the timing was to choose first $\bar{x}_{i}$ and then $C_{i}$, it is easy to verify that $C_{i}$ would depend both on $\bar{x}_{i}$ and $\bar{x}_{-i}$, and, in this case, the results would drastically change. But, with this timing, the economic interpretation does not make very much sense since it implies that criminal organizations decide on corruption before even committing crime. 
It is now interesting to analyze the properties of the equilibrium. We have a first simple result.

Proposition 2 Assume (14). Then,

(i) When $f$ the cost of bribing judges, $t$ the unit transaction cost of bribing judges or $n$ the number of criminal organizations increases, then both crime and corruption decrease.

(ii) When the net proceeds of crime $B-w_{0}$ increases, then both crime and corruption increase.

Proof. See Appendix 1.

Not surprisingly, increasing the costs of bribing judges ( $f$ and $t$ ) or giving higher wages to judges leads to less crime and to less corruption. Moreover, raising the number of criminal organizations $n$ also decreases crime and corruption because competition in the crime market becomes fiercer and it feeds back to the corruption market. Lastly, when the proceeds from crime increase then obviously crime and corruption increase.

Let us go further in the analysis. The following proposition gives our main results. ${ }^{5}$

Proposition 3 Assume (14). Then,

(i) If $\left(B-w_{0}\right)^{2} \leq 2(f+t)(n+1)^{2} /(n+2)^{2}$, for small values of $\phi S$, increasing sanctions increases corruption. But for values of $\phi S$ larger than a threshold, increasing sanctions decreases corruption. However, increasing sanctions always reduces crime.

(ii) If $2(f+t)(n+1)^{2} /(n+2)^{2}<\left(B-w_{0}\right)^{2} \leq(f+t)(n+2)^{2} / 8$, increasing sanctions reduces crime and increases corruption.

(iii) If $\left(B-w_{0}\right)^{2}>(f+t)(n+2)^{2} / 8$, increasing sanctions always increases corruption. However, for small values of $\phi S$, increasing sanctions reduces crime. But values of $\phi S$ larger than a threshold, increasing sanctions increases crime. This implies that above this threshold value of $\phi S$, increasing sanctions increase both crime and corruption.

\footnotetext{
${ }^{5}$ The technical counterpart of Proposition 3 is Proposition 7, which is given in Appendix
} 1. 
Proof. See Appendix 1.

Using Figures 1a, 1b and 1c that illustrate Proposition 3 we can give the intuition of the main results. When $\left(B-w_{0}\right)^{2} \leq 2(f+t)(n+1)^{2} /(n+2)^{2}$, the labor productivity $w_{0}$ is high, the proceeds from crime $B$ is quite low, the probability to be caught for a corrupted judge $q$ and his/her wage $w_{b}$ are quite high (see (4)) and the transaction costs $t$ to corrupt a judge are quite large. If we think of two contrasting regions of the same country, say Italy, then this case could represent the "North". If we think instead of two contrasting countries, say the United States and Colombia, then this would obviously correspond to the United States. Using Figure 1a, it is easy to see that, in this case, increasing $\phi$ the probability to be caught as a criminal (e.g. frequency of crime detection by policemen in the region) and $S$ the sanctions (e.g. loss due to imprisonment prison) always reduce crime.

However, corruption can in fact increase for low values of $\phi S$ and decrease for high values of $\phi S$. The intuition runs as follows. When $B-w_{0}$ is quite low compared to $f$ and $t$, the productivity of workers is high (implying high wages to induce them to become criminal) and the proceeds from crime is low compared to the high costs of bribing judges. Moreover, it is easy to see that the negative competition effect and the positive loot effect are not affected by a variation of $\phi S$ whereas the negative salary effect is affected since it becomes even more costly to hire criminal (they have a higher chance to be caught). So, when $\phi S$ increase, each criminal organization finds it optimal to reduce crime (or more exactly the number of criminals hired) because the costs of hiring criminals become too large compared to the benefits of crime. However, this is not true on the corruption market. Indeed, when $\phi S$ varies, the positive salary effect is affected since it becomes more costly to hire a criminal whereas the negative bribe effect is not affected since the cost of bribing judges or policemen does not depend on $\phi S$. This can easily be seen in (10) since the right hand side corresponds to the salary effect (which depends on $\phi S$ ) and the left hand side to the bribe effect (which does not depends on $\phi S$ ). In fact, differentiating the left hand side of (10) with respect to $\phi S$ yields: $C^{*}+(\phi S) \partial C^{*} / \partial(\phi S)$. The first effect $C^{*}$ is positive (i.e. for a given level of crime, when $\phi S$ increase, each criminal organization increases the level of corruption to induce people to become criminal) whereas the second one $(\phi S) \partial C^{*} / \partial(\phi S)$ is negative (i.e. when $\phi S$ increase, there is less crime and thus there is less need to corrupt 
judges or policemen so that corruption decreases). As a result, for low values of $\phi S$, crime $C^{*}$ is quite high so when $\phi S$ increases, the first effect dominates the second effect so that corruption increases. For high values of $\phi S$, when $\phi S$ increases, the second effect dominates the first one because the crime level $C$ is quite low and it is not optimal for criminal organizations to increase corruption.

When $2(f+t)(n+1)^{2} /(n+2)^{2}<\left(B-w_{0}\right)^{2} \leq(f+t)(n+2)^{2} / 8$, sanctions affect monotonically both crime and corruption. In this intermediate case, where the proceeds from crime are higher but not too high and judges are better paid, higher sanctions lead to more corruption but less crime. See Figure $1 b$ for an illustration of this case.

Let us now interpret the case when $\left(B-w_{0}\right)^{2}>(f+t)(n+2)^{2} / 8$, were labor productivity is low, the probability to be corrupted high and the proceeds of crime large. Using the above interpretation, this case would be either "Southern" Italy or Colombia. Let us use Figure 1c to understand the results. In this case, when $\phi S$ increase, it is always optimal for criminal organizations to increase corruption because the resulting gain in the reduction of criminals' wages with the fact that the net proceeds from crime $B-w_{0}$ are high are always greater than the increasing cost of bribing judges (which is not affected by $\phi S)$. In the crime market, this is not always true. Indeed, as stated above, only the salary effect is affected by $\phi S$. Take equation (11). It is easy to see the sign of $\partial C^{*} / \partial(\phi S)$ depends on $-\left(1-2 \bar{x}^{*}\right)+2 \phi S \partial \bar{x}^{*} / \partial(\phi S)$. When $\left(B-w_{0}\right)^{2}>(f+t)(n+2)^{2} / 8$, the first effect $-\left(1-2 \bar{x}^{*}\right)$ (i.e. for a given level of corruption, when $\phi S$ increase, it becomes more costly to hire criminals) is negative whereas the second one $2(\phi S) \partial \bar{x}^{*} / \partial(\phi S)$ (i.e. when $\phi S$ increases, there is more corruption and it becomes less costly to hire criminals since their probability to be sentenced if caught is lower) is positive. As a result, for low values of $\phi S$, when $\phi S$ increases, the first effect dominates the second one because the corruption is still quite low so that it becomes more costly to pay criminals and thus crime is reduced. However, for high values of $\phi S$, the second effect dominates the first one since the level corruption is quite high and thus quite effective so that crime increases.

This is our main result. In a country where crime is profitable relative to legal economic opportunities, judges are badly-paid and easy to corrupt, then for crimes that involve large sanctions (drug dealing, murders, ...), increasing 
the crime detection probability or the severity of the sanctions results in more rather than less crime. This is due to the fact that, when sanctions increase, the optimal response of criminal organizations is to increase corruption to counteract the rise in sanctions. This implies that, in countries with weak governance, the policy implications of the standard crime model may not hold and instead, as our model suggests, deterrence can only be effective ensuing a substantial cut down in corruption. Basically, the issue is that a rise in $\phi S$ can take the model into a set of the parameter space where crime and corruption are strategic complements, as long a the equilibrium bribe is bounded.

It is interesting to compare our result with that of Malik's (1990). In his model, individuals engage in socially costly activities that reduce their probability of being caught and fined. This is comparable to corruption in our model. His main finding is to show that it is not necessarily optimal to set fines for offenses as high as possible. This has the same flavor as our result (iii) in Proposition 3. There are however important differences between the two models. First, contrary to us, Malik (1990) adopts a normative perspective. He focuses on an enforcement agency that aims at reducing the social costs of avoidance activities by increasing fines. In our analysis, there is no such an agency. There is instead competition between criminal organizations. In our model, we cannot really speak about efficiency. Our results are comparative statics results. If one compares two equilibria with different levels of sanctions, then the one with the highest level of sanctions is not necessarily the one with the lowest levels of crime and corruption. Second, his main result is driven by the fact that individuals are heterogeneous ex ante in their earning abilities. In our model, all agents are identical ex ante and our main result is driven by the imperfect competition in the crime and corruption markets and the fact that crime and corruption are strategic complements. The mechanism that leads to the results is thus quite different in the two models.

\section{[Insert Figures $1 a, 1 b$ and $1 c$ here]}

We can analyze further the latter effect by investigating case (iii) in Proposition 3 . We have the following result:

Proposition 4 Assume $\left(B-w_{0}\right)^{2}>(f+t)(n+2)^{2} / 8$ and (14). Then $(i)$ the lower the labor productivity $w_{0}$ in the legal sector, $(i i)$ the higher the booty 
$B$ per crime, (iii) the easier it is to bribe law enforcers (i.e. the lower the reservation bribe $f$ and associated transaction cost $t$ ), and/or (iv) the weaker is the competition between criminal organizations (i.e. the lower is $n$ ), the lower is the threshold of $\phi S$ above which crime and corruption become strategic complements, i.e. the more likely that an increase in policing or sanctions leads to an increase in crime.

Proof. See Appendix 1.

This proposition complements our previous results. It explains why in some countries deterrence works, even if diluted by corruption, while in others it can have perverse effects. The proposition establishes that where productivity is quite low so that legal jobs are not very attractive, bribing is pervasive, and criminal organizations have high market power, then increasing policing and sanctions is more likely to trigger strategic complementarity among corruption and crime resulting in a perverse effect of deterrence.

This result contrasts with the literature that has posited optimal maximal sanctions. First, Polinski and Shavell (1979) show that if fine collection is costless and monitoring of criminal activity is costly, the optimal magnitude of fines corresponds to the maximum payable by criminals. When this maximum falls well short of the booty from crime, nonmonetary sanctions are required for deterrence. Since it is not only costly to apprehend criminals but also to punish them, Shavell (1987) proves that it is optimal for sanctions to be imposed with low frequency. Hence, in the case that the courts' information is imperfect, deterrence requires sufficiently large sanctions. The standard result is that under risk neutrality fines should be maximal. If the optimal fine is not maximal, due to risk aversion, ${ }^{6}$ the presence of corruption in Polinski and Shavell (2001) dictates higher sanctions to counter the deterrence-diluting effects of corruption. In contrast, in our model, until bribery can be eradicated, the rising of sanctions worsens the corruption and crime problems.

\footnotetext{
${ }^{6}$ Polinski and Shavell (2000) present the standard case with risk neutrality (p.50) and then discuss other reasons why maximal fines may not be optimal (p. 62-64). First, marginal deterrance may dictate heterogenous fines across criminal acts harmful in different degrees. Second, the potential for general enforcement investments yields economies of scope in monitoring inducing apprehension probabilities consistent with deterrance for sanction magnitudes below the maximal level.
} 


\section{$5 \quad$ Free entry}

One may wonder what happens to the model if we allow for free entry. In our model, it means that we investigate the formation of criminal organizations, given that each of them creates their own "local" corruption market. We would thus like to know the number of criminal organizations that will be created in a given country.

Each criminal organization that enters the crime/corruption market must pay a positive fixed cost $G$. To determine the number of criminal organizations $n^{e}$ we have to solve: $\pi^{*}(n)-G=0$, where $\pi^{*}(n)$ is given by (15). We easily obtain: ${ }^{7}$

Proposition 5 Assume

$$
\phi S<\min \left[\sqrt{(f+t) / 2}, B-w_{0}\right]
$$

and

$$
\sqrt{\frac{G}{(f+t)\left[f+t-(\phi S)^{2}\right]}}<\min \left[\frac{B-w_{0}-\phi S}{f+t-2(\phi S)^{2}}, \frac{1}{2 \phi S}\right]
$$

Then, under free entry, the equilibrium number of criminal organizations is given by:

$$
n^{e}=\frac{1}{f+t}\left[\left(B-w_{0}-\phi S\right) \sqrt{\frac{(f+t)\left[f+t-(\phi S)^{2}\right]}{G}}-\left[(f+t)-2(\phi S)^{2}\right]\right]
$$

The equilibrium number of criminals and corruption are respectively equal to:

$$
\begin{gathered}
C^{e}=\sqrt{\frac{G(f+t)}{f+t-(\phi S)^{2}}} \\
\bar{x}^{e}=\phi S \sqrt{\frac{G}{(f+t)\left[f+t-(\phi S)^{2}\right]}}
\end{gathered}
$$

In this case, increasing sanctions always increases the crime and corruption level per organization, i.e.

$$
\frac{\partial C^{e}}{\partial(\phi S)}>0 \text { and } \frac{\partial \bar{x}^{e}}{\partial(\phi S)}>0
$$

\footnotetext{
${ }^{7}$ The superscript $e$ indicates equilibrium variables under free entry.
} 
Proof. See Appendix 2.

The following comments are in order. First, as in the case with a fixed number of criminal organizations, condition (17) guarantees that $C^{e}$ and $\bar{x}^{e}$ are strictly positive and unique. Condition (18) guarantees that $n^{e}$ is strictly positive and that, at the free entry equilibrium, the market is not covered, i.e. some judges are not corrupted. As it can be seen, in order for a free-entry market to stay non-covered, it has to be that the free-entry fixed cost $G$ is bounded above. The intuition is as follows. When the fixed cost $G$ increases, there are less criminal organizations in the economy so less competition for crime. This implies that the crime, the corruption level and the profit per criminal organization increases. As a result, for the market not to be covered, i.e. $\bar{x}^{e}<1 / 2$, it has to be that $G$ is not too high. Similarly, for $n^{e}$ to be positive, i.e. some criminal organizations want to enter the market, it has to be that $G$ is not too high. These two conditions are expressed in (18). Second, when there is free entry, the number of criminal organizations $n^{e}$, the crime and corruption level per criminal organization, $C^{e}$ and $\bar{x}^{e}$, are respectively given by (19), (20) and (21). It is easy to verify that both $C^{e}$ and $\bar{x}^{e}$ increase with sanctions $\phi S$. Indeed, when sanctions increase, the competition in the crime market is reduced and thus $C^{e}$ and $\bar{x}^{e}$ increase. This is does not however increase the total level of crime $n^{e} C^{e}$ and corruption $2 n^{e} \bar{x}^{e}$ in the economy. We would like now to see if our previous result established in Proposition 3 (iii), i.e. increasing sanctions can increase both crime and corruption, is still valid with entry. The following proposition shows that it is still true.

\section{Proposition 6 If}

$$
\max \left[\frac{1}{2} \sqrt{f+t}, \frac{f+t}{B-w_{0}}\right]<\phi S<\sqrt{(f+t) / 2}
$$

and

$\frac{f+t-(\phi S)^{2}}{\phi S\left[3(f+t)-2(\phi S)^{2}\right]}<\sqrt{\frac{G}{(f+t)\left[f+t-(\phi S)^{2}\right]}}<\min \left[\frac{B-w_{0}-\phi S}{f+t-2(\phi S)^{2}}, \frac{1}{2(\phi S)}\right]$

then, under free entry, increasing sanctions increase the total levels of both crime and corruption in the economy, i.e.

$$
\frac{\partial\left(n^{e} C^{e}\right)}{\partial(\phi S)}>0 \text { and } \frac{\partial\left(2 n^{e} \bar{x}^{e}\right)}{\partial(\phi S)}>0
$$


Proof. See Appendix 2.

This proposition shows that increasing sanctions can increase both the total levels of crime and corruption in the economy if (23) holds, i.e. the fixed cost $G$ has to be bounded above and below. Indeed, as in Proposition 5, the fixed cost cannot be too large for the market not to be covered and for criminal organizations to enter the market. But, because $G$ positively affects both $C^{e}$ and $\bar{x}^{e}$, the fixed cost cannot be too low for this result to hold, otherwise increasing sanctions would reduce crime. Indeed, if the fixed cost $G$ is very low and sanctions increase, there are two effects: a low $G$ implies a high $n^{e}$, thus more competition in the crime market, but an increase in $\phi S$ reduces $n^{e}$. In this case, each criminal organization raises its level of corruption $\bar{x}^{e}$ and hires more criminals but the global effect reduces total crime $n^{e} C^{e}$ because there are less criminal organizations in the economy. If, on the contrary, $G$ is not too low, the reduction in competition in the crime market is strong enough to reverse the result.

\section{Conclusion}

This paper has spelled out the role of corruption and imperfect competition in preventing the justice system to work efficiently. Indeed, in a model where criminal organizations compete a la Cournot on the crime market and act as local monopsonists on the corruption market, we have showed that when bribing costs are small relative to crime profitability, beyond a threshold further sanctions lead to higher rather than lower crime.

We agree with Becker (1968), Ehrlich (1973), Polinski and Shavell (1979) and Levitt $(1997,1998)$ that enhancing enforcement efficiency and sanction severity in order to increase expected punishment, thereby reducing criminal activity, is important. However, when dealing with organized crime that engages in corruption to manipulate conviction probabilities, complementary measures, such as crack down on corruption or the institutionalization of checks and balances, are warranted to control the problem. Our model delivers stark conclusions with respect to the relationship between crime and corruption and as to why the standard "crime and punishment" framework may fail for some countries. Further efforts to inflict tougher sentences on criminals will just raise the rents to organized crime, when corruption is pervasive. More gener- 
ally the enforcement of property rights at large can break down once the police force and courts stop functioning properly. Beyond a threshold of corruption in the justice system, increasing returns in various types of crime may take off. This observation may explain crime dynamics in some countries (e.g. Colombia and Russia) or regions within countries (e.g. Sicily in Italy). Once this process starts, the best policy may be to contain diffusion of corruption by organized crime to neighboring jurisdictions. Before it starts, the best policy may be to try to suppress organized crime rents.

Given the complementarity between crime and corruption, and since building the required institutions for a transparent legal system can take a long time to achieve, tolerating some degree of illegality (or of a harmful activity which is legalized) can be desirable if it helps to destroy the rents of organized crime. It is interesting to observe that, in the 1920's, during prohibition in the United States, organized crime did have police, judges and politicians in its payroll. In this period of time, more monitoring and investigation of alcohol distribution only increased the rents of the business for both traffickers and corrupt "enforcers". On the one hand, in some sense, severe sanctions on alcohol consumption sowed the seeds for a powerful cartel that came to be known as the mob. On the other hand, the destruction of rents through legalization had a lasting effect in weakening the influence of organized crime on the legal system, which had facilitated all kinds of illegal subsidiary operations by the Mafia, including gambling, prostitution and racketeering.

\section{References}

[1] Bardhan, P., 1997. Corruption and development. A review of issues. Journal of Economic Literature 35, 1320-1346.

[2] Basu, K., Battacharya, S., Mishra, A., 1992. Note on bribery and the control of corruption. Journal of Public Economics 38, 349-359.

[3] Becker, G., 1968. Crime and punishment: An economic approach. Journal of Political Economy 76, 167-217.

[4] Becker G., Stigler, G., 1974. Law enforcement, malfeasance and the compensation of enforcers. Journal of Legal Studies 3, 1-19. 
[5] Besley, T., MacLaren, J., 1993. Taxes and bribery: The role of wage incentives. Economic Journal 103, 119-41.

[6] Bowles, R., Garoupa, N., 1997. Casual police corruption and the economics of crime. International Review of Law and Economics 17, 75-87.

[7] Chang, J-J., Lai, C-C., Yang, C.C., 2000. Casual police corruption and the economics of crime: Further results. International Review of Law and Economics 20, 35-51.

[8] Ehrlich, I., 1973. Participation in illegitimate activities. Journal of Political Economy 81, 521-565.

[9] Fender, J., 1999. A general equilibrium model of crime and punishment. Journal of Economic Behavior and Organization 39, 437-453.

[10] Fiorentini, G., Peltzman, S., 1996. The Economics of Organized Crime. Cambridge University Press, Cambridge.

[11] Garoupa, N., 2000. The economics of organized crime and optimal law enforcement. Economic Inquiry 38, 278-288.

[12] Garoupa, N., Jellal, M. 2002. Information, corruption and optimal law enforcement. CEPR Discussion Paper Series No. 3560.

[13] Levitt, S., 1997. Using electoral cycles to estimate the effect of police on crime. American Economic Review 87, 270-90.

[14] Levitt, S., 1998. Juvenile crime and punishment. Journal of Political Economy 106, 1156-1185.

[15] Malik, A.S., 1990. Avoidance, screening and optimum enforcement. Rand Journal of Economics 21, 341-353.

[16] Mansour, A., Marceau, N., Mongrain, S., 2001. Gangs and crime deterrence. UQAM Center for Research on Economic Fluctuations and Employment, Working Paper No. 138.

[17] Marjit, S., Shi, H., 1998. On controlling crime with corrupt officials. Journal of Economic Behavior and Organization 34, 163-172. 
[18] Mookherjee, D., Png, I., 1992. Monitoring vis-a-vis investigation in enforcement of law. American Economic Review 82, 556-65.

[19] Polinski M., Shavell, S., 1979. The optimal tradeoff between the probability and magnitude of fines. American Economic Review 69, 880-91.

[20] Polinski M., Shavell, S., 2000. The economics theory of public enforcement of law. Journal of Economic Literature 38, 45-76.

[21] Polinski M., Shavell, S., 2001. Corruption and optimal law enforcement. Journal of Public Economics 81, 1-24.

[22] Sah, R., 1991. Social osmosis and patterns of crime. Journal of Political Economy 99, 1272-1295.

[23] Salop, S., 1979. Monopolistic competition with outside goods. Bell Journal of Economics 10, 141-156.

[24] Shavell, S., 1987. The optimal use of nonmonetary sanctions as a deterrent. American Economic Review 77, 584-92. 


\section{APPENDIX 1: Proofs for the case of a fixed number of firms}

\section{Proof of Proposition 1}

First, by assuming that $f+t>2(\phi S)^{2}$ (see (14)), we guarantee that: $(i)$ the second order condition (8) is always true, $(i i)(f+t)(n+1)>2(\phi S)^{2}$. As a result, $(i i)$ implies that the denominator of $C^{*}$ and $\bar{x}^{*}$ are both strictly positive and that the equilibrium profit $\pi^{*}(n)$ given by (15) and the equilibrium wage $w^{*}(n)$ given by (16) are both strictly positive.

Second, using (12) and (13), it is easy to see that $C^{*}>0$ and $\bar{x}^{*}>0$ is equivalent to $B-w_{0}>\phi S$. This is guaranteed by (14).

Third, because we consider the case of local monopsonists, we have to check that in equilibrium some judges will not be corrupted (i.e. the market is not covered). The market is not covered iff $\bar{x}^{*}<1 / 2$. Using (12), this writes:

$$
\frac{\phi S\left(B-w_{0}-\phi S\right)}{(f+t)(n+1)-2(\phi S)^{2}}<\frac{1}{2}
$$

which is equivalent to

$$
\phi S<\frac{(f+t)(n+1)}{2\left(B-w_{0}\right)}
$$

This is the third part in the bracket in (14).

Finally, to calculate the equilibrium profit and the equilibrium criminal's wage, it suffices to plug (12) and (13) in (5) and in (3).

\section{Proof of Proposition 2}

(i) By differentiating (12) and (13), it is easy to see that

$$
\begin{array}{llll}
\frac{\partial C^{*}}{\partial f}<0 & \text { and } & \frac{\partial \bar{x}^{*}}{\partial f}<0 \\
\frac{\partial C^{*}}{\partial t}<0 & \text { and } & \frac{\partial \bar{x}^{*}}{\partial t}<0 \\
\frac{\partial C^{*}}{\partial n}<0 & \text { and } & \frac{\partial \bar{x}^{*}}{\partial n}<0
\end{array}
$$

(ii) By differentiating (12) and (13), it is easy to see that

$$
\frac{\partial C^{*}}{\partial\left(B-w_{0}\right)}>0 \quad \text { and } \quad \frac{\partial \bar{x}^{*}}{\partial\left(B-w_{0}\right)}>0
$$




\section{Proof of Proposition 3}

Before proving the result of this proposition, we need the following lemmata.

\section{Lemma 1}

(i) When $\left(B-w_{0}\right)^{2}<(f+t) / 2$,

$$
B-w_{0}<\sqrt{(f+t) / 2}<\frac{(f+t)(n+1)}{2\left(B-w_{0}\right)}
$$

(ii) When $(f+t) / 2<\left(B-w_{0}\right)^{2}<(f+t)(n+1) / 2$,

$$
\sqrt{(f+t) / 2}<B-w_{0}<\frac{(f+t)(n+1)}{2\left(B-w_{0}\right)}
$$

(iii) When $(f+t)(n+1) / 2<\left(B-w_{0}\right)^{2}<(f+t)(n+1)^{2} / 2$,

$$
\sqrt{(f+t) / 2}<\frac{(f+t)(n+1)}{2\left(B-w_{0}\right)}<B-w_{0}
$$

(iv) When $\left(B-w_{0}\right)^{2}>(f+t)(n+1)^{2} / 2$,

$$
\frac{(f+t)(n+1)}{2\left(B-w_{0}\right)}<\sqrt{(f+t) / 2}<B-w_{0}
$$

Proof. If one compares $\sqrt{(f+t) / 2}, B-w_{0}$ and $(f+t)(n+1) /\left[2\left(B-w_{0}\right)\right]$, one easily obtains:

$$
\begin{gathered}
B-w_{0} \gtrless \sqrt{(f+t) / 2} \Leftrightarrow\left(B-w_{0}\right)^{2} \gtrless(f+t) / 2 \\
B-w_{0} \gtrless \frac{(f+t)(n+1)}{2\left(B-w_{0}\right)} \Leftrightarrow\left(B-w_{0}\right)^{2} \gtrless(f+t)(n+1) / 2 \\
\sqrt{(f+t) / 2} \gtrless \frac{(f+t)(n+1)}{2\left(B-w_{0}\right)} \Leftrightarrow\left(B-w_{0}\right)^{2} \gtrless(f+t)(n+1)^{2} / 2
\end{gathered}
$$

Since, $(f+t)(n+1)^{2} / 2>(f+t)(n+1) / 2>(f+t) / 2$, the result follows. 


\section{Lemma 2}

(i) When $\left(B-w_{0}\right)^{2} \leq(f+t) / 2$, then condition (14) is equivalent to $\phi S<$ $B-w_{0}$.

(ii) When $(f+t) / 2<\left(B-w_{0}\right)^{2} \leq(f+t)(n+1)^{2} / 2$, then condition (14) is equivalent to $\phi S<\sqrt{(f+t) / 2}$.

(iii) $\left(B-w_{0}\right)^{2}>(f+t)(n+1)^{2} / 2$, then condition (14) is equivalent to $\phi S<(f+t)(n+1) /\left[2\left(B-w_{0}\right)\right]$.

Proof. By using Lemma 1 and condition (14), this is straightforward.

\section{Lemma 3 (Comparative Statics of $C^{*}$ ) Define $e^{8}$}

$$
\begin{aligned}
& (\phi S)_{1}^{C S C} \equiv B-w_{0}-\sqrt{\left(B-w_{0}\right)^{2}-(f+t)(n+1) / 2} \\
& (\phi S)_{2}^{C S C} \equiv B-w_{0}+\sqrt{\left(B-w_{0}\right)^{2}-(f+t)(n+1) / 2}
\end{aligned}
$$

(i) When $\left(B-w_{0}\right)^{2}<(f+t)(n+1) / 2$,

$$
\frac{\partial C^{*}}{\partial(\phi S)}<0, \forall \phi S
$$

(ii) When $\left(B-w_{0}\right)^{2}>(f+t)(n+1) / 2$,

$$
\begin{gathered}
\frac{\partial C^{*}}{\partial(\phi S)}<0, \text { if } \phi S<(\phi S)_{1}^{C S C} \\
\frac{\partial C^{*}}{\partial(\phi S)}>0, \text { if }(\phi S)_{1}^{C S C}<\phi S<(\phi S)_{2}^{C S C}
\end{gathered}
$$

and

$$
\frac{\partial C^{*}}{\partial(\phi S)}<0, \text { if } \phi S>(\phi S)_{2}^{C S C}
$$

Proof. By differentiating (13), we obtain:

$$
\frac{\partial C^{*}}{\partial(\phi S)}=(f+t) \frac{-2(\phi S)^{2}+4(\phi S)\left(B-w_{0}\right)-(f+t)(n+1)}{\left[(f+t)(n+1)-2(\phi S)^{2}\right]^{2}}
$$

In order to study the sign of $\partial C^{*} / \partial(\phi S)$, we have to study

$$
\Omega^{C S C}(\phi S) \equiv-2(\phi S)^{2}+4(\phi S)\left(B-w_{0}\right)-(f+t)(n+1)
$$

\footnotetext{
${ }^{8}$ The superscript $C S C$ refers to the comparative statics of $C^{*}$.
} 
The discriminant is given by: $\Delta^{C S C}=8\left[2\left(B-w_{0}\right)^{2}-(f+t)(n+1)\right]$. Two cases arise.

- If $\left(B-w_{0}\right)^{2}<(f+t)(n+1) / 2$ (i.e. $\left.\Delta^{C S C}<0\right)$, then $\Omega^{C S C}(\phi S)<0$ is always true since the graph of $\Omega^{C S C}(\phi S)$ is situated in the negative orthant. This implies that $\partial C^{*} / \partial(\phi S)<0, \forall \phi S$. This proves $(i)$.

- If $\left(B-w_{0}\right)^{2}>(f+t)(n+1) / 2$ (i.e. $\left.\Delta^{C S C}>0\right)$, then we have to study $\Omega^{C S C}(\phi S)$. The two roots are given by

$$
\begin{aligned}
& (\phi S)_{1}^{C S C}=B-w_{0}-\sqrt{\left(B-w_{0}\right)^{2}-(f+t)(n+1) / 2} \\
& (\phi S)_{2}^{C S C}=B-w_{0}+\sqrt{\left(B-w_{0}\right)^{2}-(f+t)(n+1) / 2}
\end{aligned}
$$

Since $\Omega^{C S C}(\phi S)$ is a quadratic function and the coefficient of $(\phi S)^{2},-2$, is negative, $\Omega^{C S C}(\phi S)$ is a concave function that intersects the vertical axis twice, exactly at the two roots. Thus, $\Omega^{C S C}(\phi S)$ is negative if and only if $\phi S<$ $(\phi S)_{1}^{C S C}$ or $\phi S>(\phi S)_{2}^{C S C}$ and $\Omega^{C S C}(\phi S)$ is positive if and only if $(\phi S)_{1}^{C S C}<$ $\phi S<(\phi S)_{2}^{C S C}$. This proves $(i i)$.

Now, we have to check that the comparative statics of $C^{*}$ with respect to $\phi S$ holds when condition (14) holds. We have a first result.

\section{Lemma 4}

(i) When $(f+t)(n+1) / 2<\left(B-w_{0}\right)^{2}<(f+t)(n+2)^{2} / 8$,

$$
(\phi S)_{1}^{C S C}>\sqrt{(f+t) / 2} \text { and }(\phi S)_{2}^{C S C}>\sqrt{(f+t) / 2}
$$

(ii) When $(f+t)(n+2)^{2} / 8<\left(B-w_{0}\right)^{2}<(f+t)(n+1)^{2} / 2$,

$$
(\phi S)_{1}^{C S C}<\sqrt{(f+t) / 2}<(\phi S)_{2}^{C S C}
$$

(iii) When $\left(B-w_{0}\right)^{2}>(f+t)(n+1)^{2} / 2$,

$$
(\phi S)_{1}^{C S C}<\frac{(f+t)(n+1)}{2\left(B-w_{0}\right)}<(\phi S)_{2}^{C S C}
$$

\section{Proof.}

First, let us show that, when $\left(B-w_{0}\right)^{2}>(f+t)(n+1) / 2,(\phi S)_{2}^{C S C}>$ $\sqrt{(f+t) / 2}$ and $(\phi S)_{2}^{C S C}>\frac{(f+t)(n+1)}{2\left(B-w_{0}\right)}$. 
Observe that

$$
(\phi S)_{2}^{C S C}=B-w_{0}+\sqrt{\left(B-w_{0}\right)^{2}-(f+t)(n+1) / 2}>B-w_{0}
$$

We have shown that in lemma 1 that when $\left(B-w_{0}\right)^{2}>(f+t)(n+1) / 2$, $B-w_{0}>\sqrt{(f+t) / 2}$ and $B-w_{0}>\frac{(f+t)(n+1)}{2\left(B-w_{0}\right)}$. Since $(\phi S)_{2}^{C S C}>B-w_{0}$, this implies that, when $\left(B-w_{0}\right)^{2}>(f+t)(n+1) / 2,(\phi S)_{2}^{C S C}>\sqrt{(f+t) / 2}$ and $(\phi S)_{2}^{C S C}>\frac{(f+t)(n+1)}{2\left(B-w_{0}\right)}$. This proves the second inequality of $(i),(i i)$ and (iii).

Let us prove $(i)$ and $(i i)$. $(\phi S)_{1}^{C S C} \gtrless \sqrt{(f+t) / 2}$ is equivalent to

$$
B-w_{0} \gtrless \sqrt{(f+t) / 2}+\sqrt{\left(B-w_{0}\right)^{2}-(f+t)(n+1) / 2}
$$

which, by taking the square of both sides, leads to:

$$
(f+t) n \gtrless 4 \sqrt{(f+t)\left(B-w_{0}\right)^{2} / 2-(f+t)^{2}(n+1) / 4}
$$

By taking again the square of both sides, we obtain:

$$
(f+t)(n+2)^{2} \gtrless 8\left(B-w_{0}\right)^{2}
$$

which implies that

$$
\text { When }\left(B-w_{0}\right)^{2} \lessgtr(f+t)(n+2)^{2} / 8,(\phi S)_{1}^{C S C} \gtrless \sqrt{(f+t) / 2}
$$

This proves $(i)$ and the left hand side of $(i i)$.

Let us now prove the left hand side of $(i i i) .(\phi S)_{1}^{C S C}<\frac{(f+t)(n+1)}{2\left(B-w_{0}\right)}$ is equivalent to

$$
2\left(B-w_{0}\right)^{2}-(f+t)(n+1)<2\left(B-w_{0}\right) \sqrt{\left(B-w_{0}\right)^{2}-(f+t)(n+1) / 2}
$$

The left hand side of this inequality is positive since we are in the case of $\left(B-w_{0}\right)^{2}>(f+t)(n+1)^{2} / 2>(f+t)(n+1) / 2$. We can thus take the square of both sides and obtain:

$$
\left(B-w_{0}\right)^{2}>(f+t)(n+1) / 2
$$

This is always true when $\left(B-w_{0}\right)^{2}>(f+t)(n+1)^{2} / 2$, since $(f+t)(n+$ $1)^{2} / 2>(f+t)(n+1) / 2$. As a result, when $\left(B-w_{0}\right)^{2}>(f+t)(n+1)^{2} / 2$, $(\phi S)_{1}^{C S C}<\frac{(f+t)(n+1)}{2\left(B-w_{0}\right)}$. This proves the left hand side of $(i i i)$.

We are now able to totally characterize the comparative statics of $\phi S$ on $C^{*}$. 


\section{Lemma 5 (Comparative Statics of $C^{*}$ and Condition (14))}

(i) When $\left(B-w_{0}\right)^{2} \leq(f+t) / 2$,

$$
\frac{\partial C^{*}}{\partial(\phi S)}<0, \forall \phi S<B-w_{0}
$$

(ii) When $(f+t) / 2<\left(B-w_{0}\right)^{2} \leq(f+t)(n+2)^{2} / 8$,

$$
\frac{\partial C^{*}}{\partial(\phi S)}<0, \forall \phi S<\sqrt{(f+t) / 2}
$$

(iii) When $(f+t)(n+2)^{2} / 8 \leq\left(B-w_{0}\right)^{2} \leq(f+t)(n+1)^{2} / 2$,

$$
\begin{gathered}
\frac{\partial C^{*}}{\partial(\phi S)}<0 \text {, if } \phi S<(\phi S)_{1}^{C S C}<\sqrt{(f+t) / 2} \\
\frac{\partial C^{*}}{\partial(\phi S)}>0 \text {, if }(\phi S)_{1}^{C S C}<\phi S<\sqrt{(f+t) / 2}
\end{gathered}
$$

(iv) When $\left(B-w_{0}\right)^{2}>(f+t)(n+1)^{2} / 2$,

$$
\begin{gathered}
\frac{\partial C^{*}}{\partial(\phi S)}<0, \text { if } \phi S<(\phi S)_{1}^{C S C}<\frac{(f+t)(n+1)}{2\left(B-w_{0}\right)} \\
\frac{\partial C^{*}}{\partial(\phi S)}>0, \text { if }(\phi S)_{1}^{C S C}<\phi S<\frac{(f+t)(n+1)}{2\left(B-w_{0}\right)}
\end{gathered}
$$

\section{Proof.}

(i) When $\left(B-w_{0}\right)^{2} \leq(f+t) / 2$, we know from Lemma $2(i)$ that condition (14) is: $\phi S<B-w_{0}$ and from Lemma $3(i)$ that, since $(f+t) / 2<$ $(f+t)(n+1) / 2$, we have:

$$
\frac{\partial C^{*}}{\partial(\phi S)}<0, \forall \phi S
$$

The result follows.

(ii) To show this result, we have to consider two cases:

When $(f+t) / 2<\left(B-w_{0}\right)^{2}<(f+t)(n+1) / 2$ and when $(f+t)(n+1) / 2<$ $\left(B-w_{0}\right)^{2}<(f+t)(n+2)^{2} / 8$.

Let us start with $(f+t) / 2<\left(B-w_{0}\right)^{2}<(f+t)(n+1) / 2$. We know from Lemma 2 (ii) that, since $(f+t)(n+1) / 2<(f+t)(n+1)^{2} / 2$, condition (14) is: $\phi S<\sqrt{f+t}$ and from Lemma $3(i)$ that

$$
\frac{\partial C^{*}}{\partial(\phi S)}<0, \forall \phi S
$$


The result follows.

Consider now the case when $(f+t)(n+1) / 2<\left(B-w_{0}\right)^{2}<(f+t)(n+2)^{2} / 8$. We know from Lemma 2 (ii) that, since $(f+t)(n+2)^{2} / 8<(f+t)(n+1)^{2} / 2$ and $(f+t)(n+1) / 2>(f+t) / 2$, condition (14) is: $\phi S<\sqrt{(f+t) / 2}$. Furthermore, from Lemma $4(i)$, we know that when $(f+t)(n+1) / 2<\left(B-w_{0}\right)^{2}<$ $(f+t)(n+2)^{2} / 8,(\phi S)_{1}^{C S C}>\sqrt{(f+t) / 2}$. As a result, using Lemma $3(i i)$, we have that

$$
\frac{\partial C^{*}}{\partial(\phi S)}<0, \text { if } \phi S<\sqrt{(f+t) / 2}
$$

since $\phi S$ cannot be greater than $\sqrt{(f+t) / 2}$.

Now putting together these two cases, we obtain $(i i)$.

(iii) We know from Lemma 2 (ii) that, since $(f+t)(n+2)^{2} / 8>f+$ $t$, condition (14) is: $\phi S<\sqrt{(f+t) / 2}$. We know also from Lemma 4 (ii) that when $(f+t)(n+2)^{2} / 8<\left(B-w_{0}\right)^{2}<(f+t)(n+1)^{2} / 2,(\phi S)_{1}^{C S C}<$ $\sqrt{(f+t) / 2}<(\phi S)_{2}^{C S C}$. As a result, using Lemma $3(i i)$, the result follows.

(iv) We know from Lemma 2 (iii) that, when $\left(B-w_{0}\right)^{2}>(f+t)(n+1)^{2} / 2$, condition (14) is: $\phi S<(f+t)(n+1)\left[2\left(B-w_{0}\right)\right]$. We know also from Lemma $4($ iii $)$ that when when $\left(B-w_{0}\right)^{2}>(f+t)(n+1)^{2} / 2,(\phi S)_{1}^{C S C}<\frac{(f+t)(n+1)}{2\left(B-w_{0}\right)}<$ $(\phi S)_{2}^{C S C}$. Now, using Lemma $3(i i)$, the result follows.

Let us now study the comparative statics of $\bar{x}^{*}$ with respect to $\phi S$.

\section{Lemma 6 (Comparative Statics of $\bar{x}^{*}$ ) Define $e^{9}$}

$$
(\phi S)_{1}^{C S X} \equiv \frac{(f+t)(n+1)-\sqrt{(f+t)(n+1)} \sqrt{(f+t)(n+1)-2\left(B-w_{0}\right)^{2}}}{2\left(B-w_{0}\right)}
$$

and

$$
(\phi S)_{2}^{C S X} \equiv \frac{(f+t)(n+1)+\sqrt{(f+t)(n+1)} \sqrt{(f+t)(n+1)-2\left(B-w_{0}\right)^{2}}}{2\left(B-w_{0}\right)}
$$

(i) When $\left(B-w_{0}\right)^{2}<(f+t)(n+1) / 2$,

$$
\begin{gathered}
\frac{\partial \bar{x}^{*}}{\partial(\phi S)}>0, \text { if } \phi S<(\phi S)_{1}^{C S X} \\
\frac{\partial \bar{x}^{*}}{\partial(\phi S)}<0, \text { if }(\phi S)_{1}^{C S X}<\phi S<(\phi S)_{2}^{C S X}
\end{gathered}
$$

\footnotetext{
${ }^{9}$ The superscript $C S X$ refers to the comparative statics of $\bar{x}^{*}$.
} 
and

$$
\frac{\partial \bar{x}^{*}}{\partial(\phi S)}>0, \text { if } \phi S>(\phi S)_{2}^{C S C}
$$

(ii) When $\left(B-w_{0}\right)^{2}>(f+t)(n+1) / 2$,

$$
\frac{\partial \bar{x}^{*}}{\partial(\phi S)}>0, \forall \phi S
$$

Proof. By differentiating (12), we easily obtain:

$$
\frac{\partial \bar{x}^{*}}{\partial(\phi S)}=\frac{2(\phi S)^{2}\left(B-w_{0}\right)-2 \phi S(f+t)(n+1)+(f+t)(n+1)\left(B-w_{0}\right)}{\left[(f+t)(n+1)-2(\phi S)^{2}\right]^{2}}
$$

In order to study the sign of $\partial \bar{x}^{*} / \partial(\phi S)$, we have to study

$$
\Omega^{C S X}(\phi S) \equiv 2(\phi S)^{2}\left(B-w_{0}\right)-2 \phi S(f+t)(n+1)+(f+t)(n+1)\left(B-w_{0}\right)
$$

The discriminant is given by: $\Delta^{C S X}=4(f+t)(n+1)\left[(f+t)(n+1)-2\left(B-w_{0}\right)^{2}\right]$. Two cases arise.

- If $\left(B-w_{0}\right)^{2}>(f+t)(n+1) / 2$ (i.e. $\left.\Delta^{C S X}<0\right)$, then $\Omega^{C S X}(\phi S)>0$ is always true since the graph of $\Omega^{C S X}(\phi S)$ is situated in the positive orthant. This implies that $\partial \bar{x}^{*} / \partial(\phi S)>0, \forall \phi S$. This proves $(i i)$.

- If $\left(B-w_{0}\right)^{2}<(f+t)(n+1) / 2$ (i.e. $\left.\Delta^{C S X}>0\right)$, then we have to study $\Omega^{C S X}(\phi S)$. The two roots are given by

$$
\begin{aligned}
(\phi S)_{1}^{C S X} & =\frac{(f+t)(n+1)-\sqrt{(f+t)(n+1)} \sqrt{(f+t)(n+1)-2\left(B-w_{0}\right)^{2}}}{2\left(B-w_{0}\right)} \\
(\phi S)_{2}^{C S X} & =\frac{(f+t)(n+1)+\sqrt{(f+t)(n+1)} \sqrt{(f+t)(n+1)-2\left(B-w_{0}\right)^{2}}}{2\left(B-w_{0}\right)}
\end{aligned}
$$

Since $\Omega^{C S X}(\phi S)$ is a quadratic function and the coefficient of $(\phi S)^{2}, 2\left(B-w_{0}\right)$, is positive, $\Omega^{C S X}(\phi S)$ is a convex function that intersects the vertical axe twice, at exactly the two roots. Thus, $\Omega^{C S X}(\phi S)$ is positive if and only if $\phi S<(\phi S)_{1}^{C S X}$ or $\phi S>(\phi S)_{2}^{C S X}$ and $\Omega^{C S X}(\phi S)$ is negative if and only if $(\phi S)_{1}^{C S X}<\phi S<(\phi S)_{2}^{C S X}$. This proves $(i)$.

\section{Lemma 7}

(i) When $\left(B-w_{0}\right)^{2} \leq(f+t) / 2$,

$$
(\phi S)_{1}^{C S X}<B-w_{0}<(\phi S)_{2}^{C S X}
$$


(ii) When $(f+t) / 2<\left(B-w_{0}\right)^{2} \leq 2(f+t)(n+1)^{2} /(n+2)^{2}$,

$$
(\phi S)_{1}^{C S X}<\sqrt{(f+t) / 2}<(\phi S)_{2}^{C S X}
$$

(iii) When $2(f+t)(n+1)^{2} /(n+2)^{2}<\left(B-w_{0}\right)^{2}<(f+t)(n+1) / 2$,

$$
(\phi S)_{1}^{C S X}>\sqrt{(f+t) / 2} \text { and }(\phi S)_{2}^{C S X}>\sqrt{(f+t) / 2}
$$

\section{Proof.}

Let us first study the conditions on $(\phi S)_{2}^{C S X}$ in $(i),(i i)$ and $(i i i) \cdot(\phi S)_{2}^{C S X}>$ $B-w_{0}$ is equivalent to

$\sqrt{(f+t)(n+1)} \sqrt{(f+t)(n+1)-2\left(B-w_{0}\right)^{2}}>2\left(B-w_{0}\right)^{2}-(f+t)(n+1)$

When $\left(B-w_{0}\right)^{2}<(f+t)(n+1) / 2$, this inequality is always true since the left hand side is positive and the right hand side is negative. Thus, when $\left(B-w_{0}\right)^{2}<(f+t)(n+1) / 2,(\phi S)_{2}^{C S X}>B-w_{0}$. Since when $(f+t) / 2<$ $\left(B-w_{0}\right)^{2}<(f+t)(n+1) / 2, B-w_{0}>\sqrt{(f+t) / 2}$, this implies that $(\phi S)_{2}^{C S X}>$ $\sqrt{(f+t) / 2}$. We have thus shown that

When $(f+t) / 2<\left(B-w_{0}\right)^{2}<(f+t)(n+1) / 2,(\phi S)_{2}^{C S X}>\sqrt{(f+t) / 2}$ and

$$
\text { When }\left(B-w_{0}\right)^{2}<(f+t) / 2,(\phi S)_{2}^{C S X}>B-w_{0}
$$

This demonstrates $(i),(i i)$ and $(i i i)$ for $(\phi S)_{2}^{C S X}$.

Let us now prove the results for $(\phi S)_{1}^{C S X}$. We start with $(i)$ when $(B-$ $\left.w_{0}\right)^{2}<(f+t) / 2$. $(\phi S)_{1}^{C S X}<B-w_{0}$ is equivalent to

$$
\frac{(f+t)(n+1)-\sqrt{(f+t)(n+1)} \sqrt{(f+t)(n+1)-2\left(B-w_{0}\right)^{2}}}{2\left(B-w_{0}\right)}<B-w_{0}
$$

which can be written as

$$
(f+t)(n+1)-2\left(B-w_{0}\right)^{2}<2 \sqrt{(f+t)(n+1)} \sqrt{(f+t)(n+1)-2\left(B-w_{0}\right)^{2}}
$$

Since the left hand side of this inequality is positive when $\left(B-w_{0}\right)^{2}<$ $(f+t) / 2$, we can take the square of both sides and obtain:

$$
4\left(B-w_{0}\right)^{2}\left[\left(B-w_{0}\right)^{2}-(f+t)(n+1)\right]<3(f+t)^{2}(n+1)^{2}
$$


Since when $\left(B-w_{0}\right)^{2}<(f+t) / 2,\left(B-w_{0}\right)^{2}-(f+t)(n+1)<0$, this inequality is always true. We have shown that, when $\left(B-w_{0}\right)^{2}<(f+t) / 2$, $(\phi S)_{1}^{C S X}<B-w_{0}$. This proves $(i)$ for $(\phi S)_{1}^{C S X}$.

Let us now prove $(i i)$ and $(i i i)$ for $(\phi S)_{1}^{C S X}$. $(\phi S)_{1}^{C S X} \gtrless \sqrt{(f+t) / 2}$ is equivalent to

$(f+t)(n+1) \gtrless \sqrt{(f+t)(n+1)} \sqrt{(f+t)(n+1)-2\left(B-w_{0}\right)^{2}}+2\left(B-w_{0}\right) \sqrt{(f+t) / 2}$

By taking the square of both sides we obtain:

$$
\left(B-w_{0}\right)(f+t) n \gtrless 2 \sqrt{(f+t)^{3}(n+1)^{2} / 2-\left(B-w_{0}\right)^{2}(f+t)^{2}(n+1)}
$$

By taking again the square of both sides we obtain:

$$
\left(B-w_{0}\right)^{2}(n+2)^{2} \gtrless 2(f+t)(n+1)^{2}
$$

or equivalently

$$
\left(B-w_{0}\right)^{2} \gtrless 2(f+t) \frac{(n+1)^{2}}{(n+2)^{2}}
$$

Thus:

When $(f+t) / 2 \leq\left(B-w_{0}\right)^{2}<2(f+t) \frac{(n+1)^{2}}{(n+2)^{2}},(\phi S)_{1}^{C S X}<\sqrt{(f+t) / 2}$

When $2(f+t) \frac{(n+1)^{2}}{(n+2)^{2}} \leq\left(B-w_{0}\right)^{2}<(f+t)(n+1) / 2,(\phi S)_{1}^{C S X}>\sqrt{(f+t) / 2}$.

This proves $(i i)$ and $(i i i)$ for $(\phi S)_{1}^{C S X}$.

We are now able to completely characterize the comparative statics of $\bar{x}^{*}$ with respect to $\phi S$. We have: 


\section{Lemma 8 (Comparative Statics of $\bar{x}^{*}$ and Condition (14))}

(i) When $\left(B-w_{0}\right)^{2} \leq(f+t) / 2$,

$$
\begin{gathered}
\frac{\partial \bar{x}^{*}}{\partial(\phi S)}>0, \text { if } \phi S<(\phi S)_{1}^{C S X}<B-w_{0} \\
\frac{\partial \bar{x}^{*}}{\partial(\phi S)}<0, \text { if }(\phi S)_{1}^{C S X}<\phi S<B-w_{0}
\end{gathered}
$$

(ii) When $(f+t) / 2<\left(B-w_{0}\right)^{2} \leq 2(f+t)(n+1)^{2} /(n+2)^{2}$,

$$
\begin{gathered}
\frac{\partial \bar{x}^{*}}{\partial(\phi S)}>0, \text { if } \phi S<(\phi S)_{1}^{C S X}<\sqrt{(f+t) / 2} \\
\frac{\partial \bar{x}^{*}}{\partial(\phi S)}<0, \text { if }(\phi S)_{1}^{C S X}<\phi S<\sqrt{(f+t) / 2}
\end{gathered}
$$

(iii) When $2(f+t)(n+1)^{2} /(n+2)^{2}<\left(B-w_{0}\right)^{2} \leq(f+t)(n+1)^{2} / 2$,

$$
\frac{\partial \bar{x}^{*}}{\partial(\phi S)}>0, \forall \phi S<\sqrt{(f+t) / 2}
$$

(iv) When $\left(B-w_{0}\right)^{2}>(f+t)(n+1)^{2} / 2$,

$$
\frac{\partial \bar{x}^{*}}{\partial(\phi S)}>0, \forall \phi S<\frac{(f+t)(n+1)}{2\left(B-w_{0}\right)}
$$

\section{Proof.}

(i) We know from Lemma $2(i)$ that, when $\left(B-w_{0}\right)^{2}<(f+t) / 2$, condition (14) is: $\phi S<\left(B-w_{0}\right)$. We know also from Lemma $7(i)$ that when when $\left(B-w_{0}\right)^{2}<(f+t) / 2,(\phi S)_{1}^{C S X}<B-w_{0}<(\phi S)_{2}^{C S X}$. Now, since $(f+t) / 2<$ $(f+t)(n+1) / 2$, using Lemma $6(i)$, the result follows.

(ii) We know from Lemma 2 (ii) that, since $(f+t) / 2<2(f+t)(n+$ $1)^{2} /(n+2)^{2}<(f+t)(n+1)^{2} / 2$, condition (14) is: $\phi S<\sqrt{(f+t) / 2}$. We know also from Lemma 7 (ii) that when $(f+t) / 2<\left(B-w_{0}\right)^{2}<2(f+t)(n+$ $1)^{2} /(n+2)^{2},(\phi S)_{1}^{C S X}<\sqrt{(f+t) / 2}<(\phi S)_{2}^{C S X}$. Now, since $2(f+t)(n+$ $1)^{2} /(n+2)^{2}<(f+t)(n+1) / 2$, using Lemma $6(i)$, the result follows.

(iii) To show this result, we have to consider two cases:

When $2(f+t)(n+1)^{2} /(n+2)^{2}<\left(B-w_{0}\right)^{2}<(f+t)(n+1) / 2$ and when $(f+t)(n+1) / 2<\left(B-w_{0}\right)^{2}<(f+t)(n+1)^{2} / 2$.

Let us start with $2(f+t)(n+1)^{2} /(n+2)^{2}<\left(B-w_{0}\right)^{2}<(f+t)(n+1) / 2$. We know from Lemma $2(i i)$ that, in this case, condition (14) is: $\phi S<\sqrt{(f+t) / 2}$. 
We also know from Lemma 7 (iii) that when $2(f+t)(n+1)^{2} /(n+2)^{2}<$ $\left(B-w_{0}\right)^{2}<(f+t)(n+1) / 2,(\phi S)_{1}^{C S X}>\sqrt{(f+t) / 2}$. Using Lemma $6(i)$, the result follows.

Consider now the case when $(f+t)(n+1) / 2<\left(B-w_{0}\right)^{2}<(f+t)(n+1)^{2} / 2$. We know from Lemma 2 (ii) that, when $(f+t)(n+1) / 2<\left(B-w_{0}\right)^{2}<$ $(f+t)(n+1)^{2} / 2$, condition (14) is: $\phi S<\sqrt{(f+t) / 2}$. Furthermore, from Lemma $6(i i)$, we know that when $\left(B-w_{0}\right)^{2}>(f+t)(n+1) / 2, \frac{\partial \bar{x}^{*}}{\partial(\phi S)}>0$, $\forall \phi S$. The result follows.

Now putting together these two cases, we obtain (iii).

(iv) We know from Lemma 2 (iii) that, when $\left(B-w_{0}\right)^{2}>(f+t)(n+1)^{2} / 2$, condition (14) is: $\phi S<(f+t)(n+1) /\left[2\left(B-w_{0}\right)\right]$. Now, using Lemma 6 and observing that $(f+t)(n+1) / 2<(f+t)(n+1)^{2} / 2$, the resul follows.

Finally, by observing that

$(f+t) / 2<2(f+t)(n+1)^{2} /(n+2)^{2}<(f+t)(n+2)^{2} / 8<(f+t)(n+1)^{2} / 2$

and putting together Lemma 5 and Lemma 8, we obtain the following result:

\section{Proposition 7}

(i) When $\left(B-w_{0}\right)^{2} \leq(f+t) / 2$,

$$
\begin{gathered}
\frac{\partial C^{*}}{\partial(\phi S)}<0, \forall \phi S<B-w_{0} \\
\frac{\partial \bar{x}^{*}}{\partial(\phi S)}>0, \text { if } \phi S<(\phi S)_{1}^{C S X}<B-w_{0} \\
\frac{\partial \bar{x}^{*}}{\partial(\phi S)}<0, \text { if }(\phi S)_{1}^{C S X}<\phi S<B-w_{0}
\end{gathered}
$$

(ii) When $(f+t) / 2<\left(B-w_{0}\right)^{2} \leq 2(f+t)(n+1)^{2} /(n+2)^{2}$,

$$
\begin{gathered}
\frac{\partial C^{*}}{\partial(\phi S)}<0, \forall \phi S<\sqrt{(f+t) / 2} \\
\frac{\partial \bar{x}^{*}}{\partial(\phi S)}>0, \text { if } \phi S<(\phi S)_{1}^{C S X}<\sqrt{(f+t) / 2} \\
\frac{\partial \bar{x}^{*}}{\partial(\phi S)}<0, \text { if }(\phi S)_{1}^{C S X}<\phi S<\sqrt{(f+t) / 2}
\end{gathered}
$$


(iii) When $2(f+t)(n+1)^{2} /(n+2)^{2}<\left(B-w_{0}\right)^{2} \leq(f+t)(n+2)^{2} / 8$,

$$
\frac{\partial C^{*}}{\partial(\phi S)}<0 \text { and } \frac{\partial \bar{x}^{*}}{\partial(\phi S)}>0, \forall \phi S<\sqrt{(f+t) / 2}
$$

(iv) When $(f+t)(n+2)^{2} / 8<\left(B-w_{0}\right)^{2} \leq(f+t)(n+1)^{2} / 2$,

$$
\begin{gathered}
\frac{\partial C^{*}}{\partial(\phi S)}<0, \text { if } \phi S<(\phi S)_{1}^{C S C}<\sqrt{(f+t) / 2} \\
\frac{\partial C^{*}}{\partial(\phi S)}>0, \text { if }(\phi S)_{1}^{C S C}<\phi S<\sqrt{(f+t) / 2} \\
\frac{\partial \bar{x}^{*}}{\partial(\phi S)}>0, \forall \phi S<\sqrt{(f+t) / 2}
\end{gathered}
$$

(v) When $\left(B-w_{0}\right)^{2}>(f+t)(n+1)^{2} / 2$,

$$
\begin{gathered}
\frac{\partial C^{*}}{\partial(\phi S)}<0, \text { if } \phi S<(\phi S)_{1}^{C S C}<\frac{(f+t)(n+1)}{2\left(B-w_{0}\right)} \\
\frac{\partial C^{*}}{\partial(\phi S)}>0, \text { if }(\phi S)_{1}^{C S C}<\phi S<\frac{(f+t)(n+1)}{2\left(B-w_{0}\right)} \\
\frac{\partial \bar{x}^{*}}{\partial(\phi S)}>0, \forall \phi S<\frac{(f+t)(n+1)}{2\left(B-w_{0}\right)}
\end{gathered}
$$

It is easy to see that Proposition 7 is the technical counterpart of Proposition 3 .

\section{$\underline{\text { Proof of Proposition } 4}$}

(i) Let us start with $w_{0}$. By differentiating the threshold

$$
(\phi S)_{1}^{C S C} \equiv B-w_{0}-\sqrt{\left(B-w_{0}\right)^{2}-(f+t)(n+1) / 2}
$$

we obtain

$$
\frac{\partial(\phi S)_{1}^{C S C}}{\partial w_{0}}=-1+\frac{B-w_{0}}{\sqrt{\left(B-w_{0}\right)^{2}-(f+t)(n+1) / 2}}>0
$$

(ii) For the booty $B$ we have:

$$
\frac{\partial(\phi S)_{1}^{C S C}}{\partial B}=1-\frac{B-w_{0}}{\sqrt{\left(B-w_{0}\right)^{2}-(f+t)(n+1) / 2}}<0
$$


(iii) For $f$ and $t$, by differentiating the threshold, we obtain:

$$
\frac{\partial(\phi S)_{1}^{C S C}}{\partial f}=\frac{\partial(\phi S)_{1}^{C S C}}{\partial t}=\frac{1}{4} \frac{(n+1)}{\sqrt{\left(B-w_{0}\right)^{2}-(f+t)(n+1) / 2}}>0
$$

(iv) Finally, for $n$, we have:

$$
\frac{\partial(\phi S)_{1}^{C S C}}{\partial n}=\frac{1}{4} \frac{(f+t)}{\sqrt{\left(B-w_{0}\right)^{2}-(f+t)(n+1) / 2}}>0
$$




\section{APPENDIX 2: Proofs for the case of free entry}

\section{Proof of Proposition 5}

To calculate $n^{*}$, it suffices to solve $\pi^{*}(n)-G=0$, where $\pi^{*}(n)$ is given by (15). We easily obtain (19).

We have then to study the sign of $n^{*}$. Because of $(14), 2(\phi S)^{2}-(f+t)<0$. Thus, $n^{*}>0$ if and only if

$$
\left(B-w_{0}-\phi S\right) \sqrt{\frac{(f+t)\left(f+t-(\phi S)^{2}\right)}{G}}>(f+t)-2(\phi S)^{2}
$$

which is equivalent to

$$
\sqrt{\frac{G}{(f+t)\left[f+t-(\phi S)^{2}\right]}}<\frac{B-w_{0}-\phi S}{f+t-2(\phi S)^{2}}
$$

which is the first part of (18).

To calculate the equilibrium values of $C^{e}$ and $\bar{x}^{e}$, it suffices to plug $n^{*}$, which is given by (19) in (13) and (12) respectively.

We also have to check that, at the free-entry equilibrium, the market is not covered, i.e. $\bar{x}^{e}<1 / 2$. Using (21), we easily obtain

$$
\sqrt{\frac{G}{(f+t)\left[f+t-(\phi S)^{2}\right]}}<\frac{1}{2(\phi S)}
$$

which is the second part of (18).

Finally, by differentiating (20) and (21), we easily obtain:

$$
\begin{gathered}
\frac{\partial C^{e}}{\partial(\phi S)}=\phi S \sqrt{\frac{(f+t) G}{\left[f+t-(\phi S)^{2}\right]^{3}}}>0 \\
\frac{\partial \bar{x}^{e}}{\partial(\phi S)}=\sqrt{\frac{(f+t) G}{(f+t)\left[f+t-(\phi S)^{2}\right]^{3}}}>0
\end{gathered}
$$




\section{Proof of Proposition 6}

First, by differentiating (19), (20) and (21), we obtain:

$$
\begin{gathered}
(f+t) \frac{\partial n^{*}}{\partial(\phi S)}=4(\phi S)-\sqrt{\frac{(f+t)\left[f+t-(\phi S)^{2}\right]}{G}\left[1+\frac{\phi S\left(B-w_{0}-\phi S\right)}{f+t-(\phi S)^{2}}\right]} \\
\frac{\partial C^{e}}{\partial(\phi S)}=\frac{(f+t) \phi S}{\left[f+t-(\phi S)^{2}\right]} \sqrt{\frac{G}{(f+t)\left[f+t-(\phi S)^{2}\right]}} \\
\frac{\partial \bar{x}^{e}}{\partial(\phi S)}=\frac{(f+t)}{\left[f+t-(\phi S)^{2}\right]} \sqrt{\frac{G}{(f+t)\left[f+t-(\phi S)^{2}\right]}}
\end{gathered}
$$

Second, we would like to see how the total level of crime $n^{*} C^{*}$ and corruption $2 n^{*} \bar{x}^{*}$ are affected by $\phi S$. We have:

$$
\begin{gathered}
\frac{\partial\left(n^{e} C^{e}\right)}{\partial(\phi S)}=n^{e} \frac{\partial C^{e}}{\partial(\phi S)}+C^{e} \frac{\partial n^{e}}{\partial(\phi S)} \\
=\sqrt{\frac{G}{\left[f+t-(\phi S)^{2}\right](f+t)}\left[4(\phi S)-\frac{\phi S\left[(f+t)-2(\phi S)^{2}\right]}{\left[f+t-(\phi S)^{2}\right]}-\sqrt{\frac{(f+t)\left[f+t-(\phi S)^{2}\right]}{G}}\right]}
\end{gathered}
$$

Thus the sign of $\frac{\partial\left(n^{e} C^{e}\right)}{\partial(\phi S)}$ is the same as

$$
4(\phi S)-\frac{\phi S\left[(f+t)-2(\phi S)^{2}\right]}{\left[f+t-(\phi S)^{2}\right]}-\sqrt{\frac{(f+t)\left[f+t-(\phi S)^{2}\right]}{G}}
$$

Thus

$$
\frac{\partial\left(n^{e} C^{e}\right)}{\partial(\phi S)} \gtrless 0 \Leftrightarrow \sqrt{\frac{G}{(f+t)\left[f+t-(\phi S)^{2}\right]}} \gtrless \frac{f+t-(\phi S)^{2}}{4(\phi S)\left[f+t-(\phi S)^{2}\right]-\phi S\left[f+t-2(\phi S)^{2}\right]}
$$

or equivalently

$$
\frac{\partial\left(n^{e} C^{e}\right)}{\partial(\phi S)} \gtrless 0 \Leftrightarrow \sqrt{\frac{G}{(f+t)\left[f+t-(\phi S)^{2}\right]}} \gtrless \frac{f+t-(\phi S)^{2}}{\phi S\left[3(f+t)-2(\phi S)^{2}\right]}
$$

As a result,

$$
\frac{\partial\left(n^{e} C^{e}\right)}{\partial(\phi S)}>0 \Leftrightarrow \sqrt{\frac{G}{(f+t)\left[f+t-(\phi S)^{2}\right]}}>\frac{f+t-(\phi S)^{2}}{\phi S\left[3(f+t)-2(\phi S)^{2}\right]}
$$


Similarly, we have:

$$
\begin{gathered}
\frac{\partial\left(2 n^{e} \bar{x}^{e}\right)}{\partial(\phi S)}=2\left[n^{e} \frac{\partial \bar{x}^{e}}{\partial(\phi S)}+\bar{x}^{e} \frac{\partial n^{e}}{\partial(\phi S)}\right] \\
=\frac{2}{f+t} \sqrt{\frac{G}{(f+t)\left[f+t-(\phi S)^{2}\right]}} \\
{\left[\left(B-w_{0}-2 \phi S\right) \sqrt{\frac{(f+t)\left[f+t-(\phi S)^{2}\right]}{G}}\right.} \\
\left.+\frac{\left[f+t-(\phi S)^{2}\right]\left[4(\phi S)^{2}-(f+t)\right]+(\phi S)^{2}(f+t)}{\left[f+t-(\phi S)^{2}\right]}\right]
\end{gathered}
$$

Thus the sign of $\frac{\partial\left(n^{e} \bar{x}^{e}\right)}{\partial(\phi S)}$ is the same as the sign of

$$
\begin{aligned}
& \left(B-w_{0}-2 \phi S\right) \sqrt{\frac{(f+t)\left[f+t-(\phi S)^{2}\right]}{G}} \\
& +\frac{\left[f+t-(\phi S)^{2}\right]\left[4(\phi S)^{2}-(f+t)\right]+(\phi S)^{2}(f+t)}{\left[f+t-(\phi S)^{2}\right]}
\end{aligned}
$$

which is always positive using (22). Thus,

$$
\frac{\partial\left(n^{e} \bar{x}^{e}\right)}{\partial(\phi S)}>0
$$

We need that this result holds under conditions (17) and (18), which are given by:

$$
\phi S<\min \left[\sqrt{(f+t) / 2}, B-w_{0}\right]
$$

and

$$
\sqrt{\frac{G}{(f+t)\left[f+t-(\phi S)^{2}\right]}}<\min \left[\frac{B-w_{0}-\phi S}{f+t-2(\phi S)^{2}}, \frac{1}{2 \phi S}\right]
$$

Let us start with condition (18). Denote by

$$
A \equiv \frac{B-w_{0}-\phi S}{f+t-2(\phi S)^{2}} \text { and } E \equiv \frac{1}{2 \phi S}
$$

We have that

$$
\frac{\partial\left(n^{e} C^{e}\right)}{\partial(\phi S)}>0 \text { and } \frac{\partial\left(n^{e} \bar{x}^{e}\right)}{\partial(\phi S)}>0
$$




$$
\sqrt{\frac{G}{(f+t)\left[f+t-(\phi S)^{2}\right]}}>\frac{f+t-(\phi S)^{2}}{\phi S\left[3(f+t)-2(\phi S)^{2}\right]} \equiv D
$$

which, using (18), implies that

$$
\frac{f+t-(\phi S)^{2}}{\phi S\left[3(f+t)-2(\phi S)^{2}\right]}<\sqrt{\frac{G}{(f+t)\left[f+t-(\phi S)^{2}\right]}}<\min \left[\frac{B-w_{0}-\phi S}{f+t-2(\phi S)^{2}}, \frac{1}{2(\phi S)}\right]
$$

This is (23). We thus need to check that $D<\min [A, E]$. We have:

$$
\begin{gathered}
D<E \Leftrightarrow \frac{f+t-(\phi S)^{2}}{\phi S\left[3(f+t)-2(\phi S)^{2}\right]}<\frac{1}{2(\phi S)} \Leftrightarrow 2<3 . \text { Thus } D<E \text { is always true } \\
D<A \Leftrightarrow \frac{f+t-(\phi S)^{2}}{\phi S\left[3(f+t)-2(\phi S)^{2}\right]}<\frac{B-w_{0}-\phi S}{f+t-2(\phi S)^{2}} \\
\Leftrightarrow \frac{f+t-(\phi S)^{2}}{\phi S} \frac{1}{3(f+t)-2(\phi S)^{2}}<\frac{1}{f+t-2(\phi S)^{2}}\left(B-w_{0}-\phi S\right)
\end{gathered}
$$

Since

$$
\frac{1}{3(f+t)-2(\phi S)^{2}}<\frac{1}{f+t-2(\phi S)^{2}}
$$

we need to show that

$$
\frac{f+t-(\phi S)^{2}}{\phi S}<B-w_{0}-\phi S
$$

which is equivalent to

$$
B-w_{0}>\frac{f+t}{\phi S}
$$

This is part of condition (22). Observe that $B-w_{0}>(f+t) /(\phi S)$ implies that $B-w_{0}>\phi S$ since $f+t>2(\phi S)^{2}$.

Let us now check if condition (17) holds. Because $B-w_{0}>(f+t) /(\phi S)$ implies that $B-w_{0}>\phi S$, it is easy to see that condition (17) is included in (22). 
Figure la: Case when $\left(\mathrm{B}-\mathrm{w}_{0}\right)^{2} \leq 2(\mathrm{f}+\mathrm{t}){\frac{(\mathrm{n}+1)^{2}}{(\mathrm{n}+2)^{2}}}^{2}$

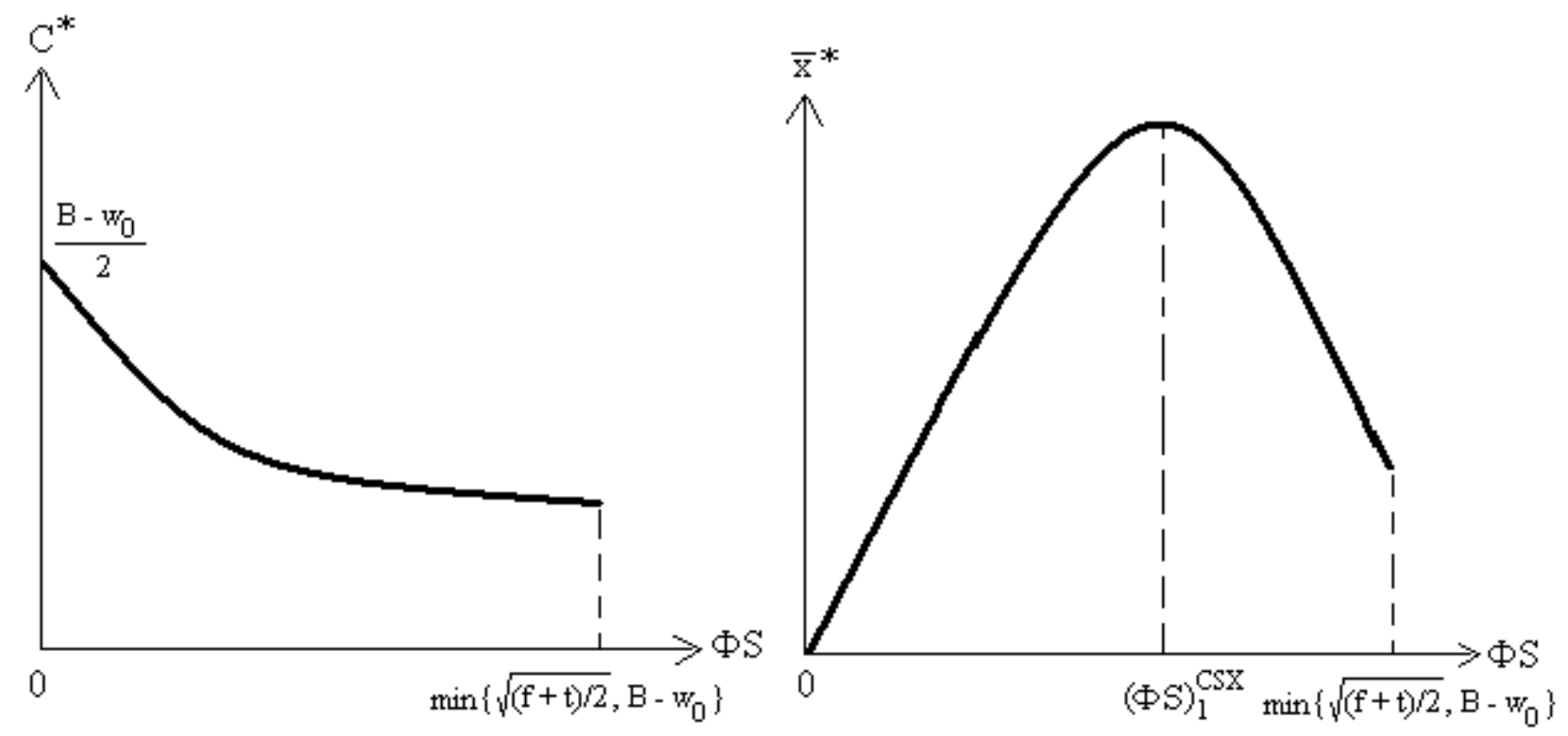


Figure 1b: Case when $2(\mathrm{f}+\mathrm{t}) \frac{(\mathrm{n}+1)^{2}}{(\mathrm{n}+2)^{2}}<\left(\mathrm{B}-\mathrm{w}_{0}\right)^{2} \leq(\mathrm{f}+\mathrm{t}) \frac{(\mathrm{n}+2)^{2}}{8}$

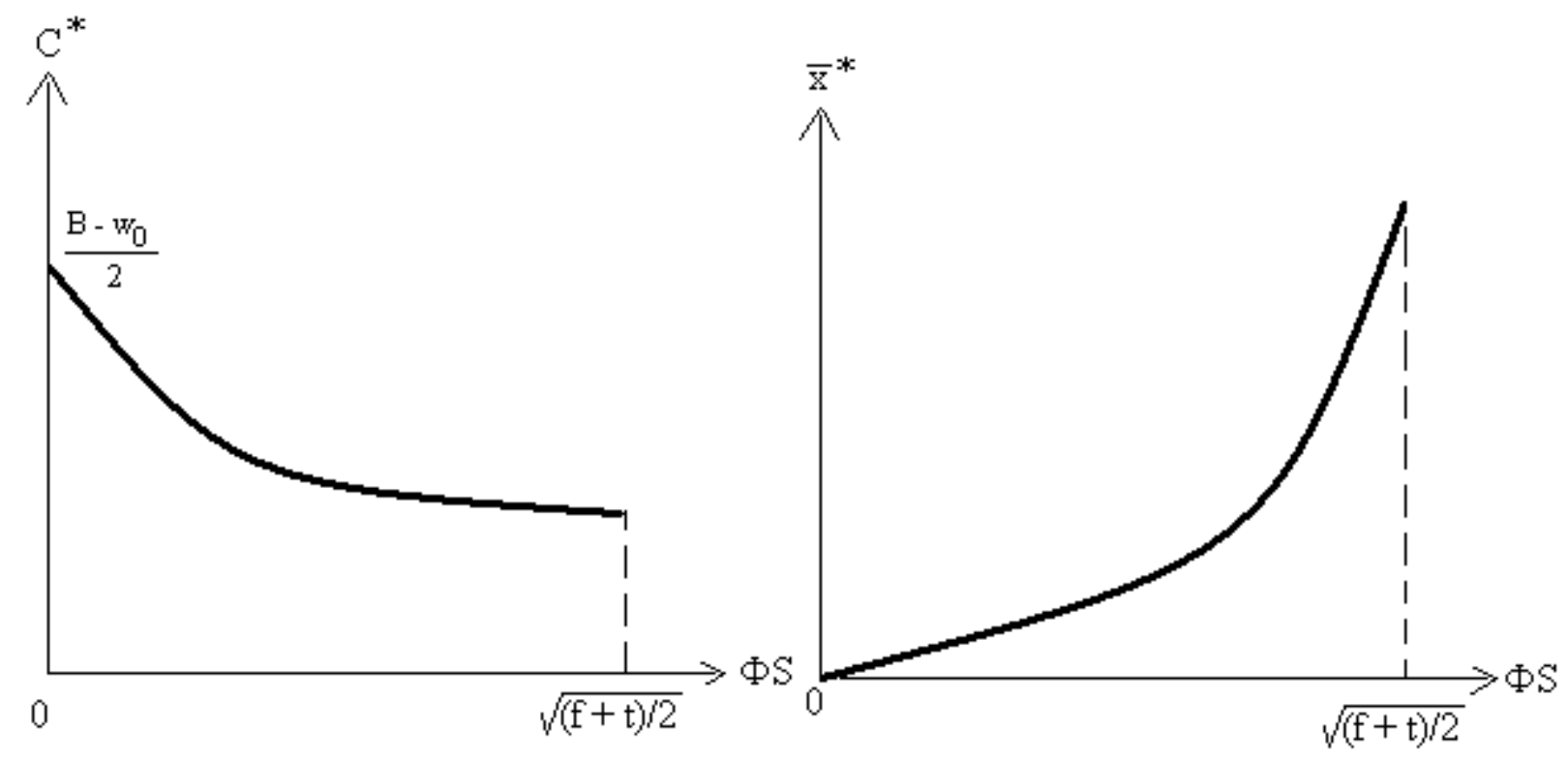


Figure 1c: Case when $\left(\mathrm{B}-\mathrm{w}_{0}\right)^{2}>(\mathrm{f}+\mathrm{t}) \frac{(\mathrm{n}+2)^{2}}{8}$
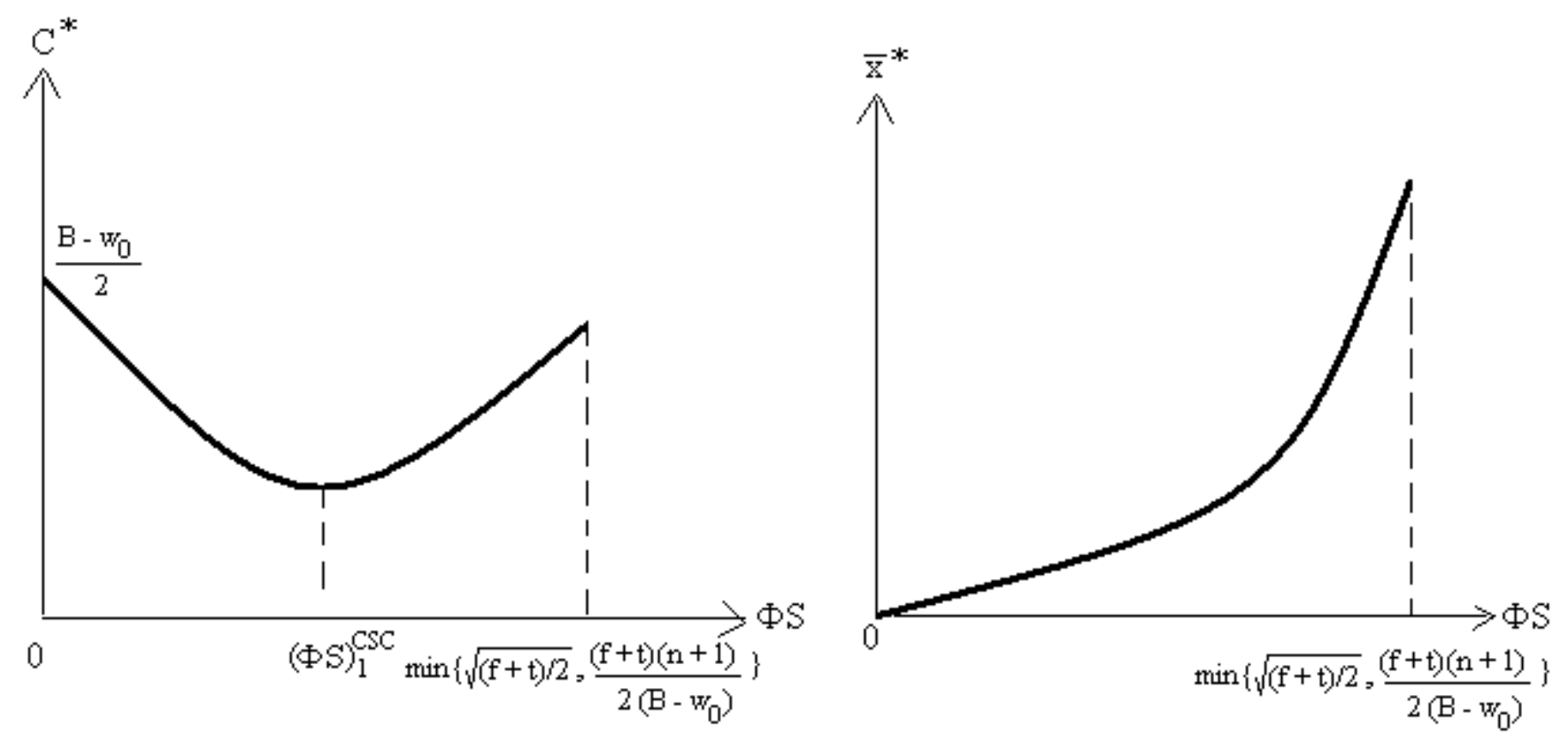